\title{
Hybrid of DNA-targeting Chlorambucil with Pt(IV) Species to Reverse Drug Resistance
}

\author{
Feihong Chen, ${ }^{1}$ Gang Xu, ${ }^{1}$ Xiaodong Qin, Xiufeng Jin, and Shaohua Gou \\ Jiangsu Province Hi-Tech Key Laboratory for Biomedical Research, Pharmaceutical Research Center and School of Chemistry \\ and Chemical Engineering, Southeast University, Nanjing, China
}

Received June 21, 2017; accepted September 11, 2017

\section{ABSTRACT}

Two hybrids of $\mathrm{Pt}(\mathrm{IV})$ species were designed and prepared by addition of a chlorambucil unit to the axial positions of the $\mathrm{Pt}(\mathrm{IV})$ complexes derived from DN603 and DN604. In vitro studies of two hybrids against two pairs of cisplatin sensitive and resistant cancer cell lines indicated that compound $\mathbf{5}$ had superior antitumor activity to cisplatin and chlorambucil via suppressing DNA damage repair to reverse drug resistance. Mechanistic investigation suggested that the potent antitumor activity of compound $\mathbf{5}$ arose from its major suppression of CK2-mediated
MRE11-RAD50-NBS1(MRN) complex promotion of DNA doublestrand break (DSB) repair. In nude mice with A549/CDDP xenografts, compound $\mathbf{5}$ exhibited higher anticancer efficacy than cisplatin and chlorambucil by reversing drug resistance, displayed improved effectiveness, and had no toxicity effects. Overall, compound $\mathbf{5}$ is a promising drug candidate, which could promote the anticancer activity and reverse drug resistance by attenuating CK2-induced MRN-dependent DSB repair.

\section{Introduction}

DNA-damaged agents are essential components of the most potent anticancer chemotherapeutics widely applied in clinic. Pt(II)-based chemotherapy drugs such as cisplatin, carboplatin, and oxaliplatin have been proven to function via triggering persistent DNA damage to induce cell death (Rosenberg et al., 1969). The DNA damage induced by such DNA-targeted agents could be survived by specific DNA damage repair pathways, thus leading to innate and acquired resistances to limit the clinical applications of DNA-targeted agents (Cobo et al., 2007; O'Grady et al., 2014). It is also well known that severe side effects of cisplatin against gastrointestinal tract and kidneys have limited its wide usage (Klein and Hambley, 2009), which be mitigated via structural modification. Therefore, carboplatin was designed to decrease the adverse effects of cisplatin, which could be attributed to the inclusion of 1,1-cyclobutyldicaboxylate as the leaving group. As a result, the leaving ligand plays a significant role in determining the toxicity and side effects of a platinum drug. With the purpose of retaining the advantage of 1,1-cyclobutanedicarboxylate as a leaving ligand and also improving the kinetic properties of the resulting platinum complexes, we have introduced a carbonyl

We are grateful to the National Natural Science Foundation of China [Grant 21571033 and 81503099] for financial aid for this work. The research was also supported by Jiangsu Province Natural Science Foundation [Grant BK20150643]

${ }^{1}$ F.C. and G.X. contributed equally to this article.

https://doi.org/10.1124/jpet.117.243451. group to the skeleton of 1,1-cyclobutanedicarboxylate, in which the functionalized moiety (carbonyl group) could achieve the desired balance between hydrophilicity and lipophilicity of the resulting platinum complex and may improve the kinetic properties as well as the DNA-binding ability of the derivatives (Zhao et al., 2014). Such platinum complexes, named DN603 and DN604 (Fig. 1, top), have been investigated, and subsequent researches demonstrated that DN604 could exhibit significant anticancer activity and reverse cisplatin resistance in cancer chemotherapeutics as well.

Chlorambucil, a member of the nitrogen mustard class of lipophilic DNA alkylating agents, is widely used for the treatment of human solid tumors (Chabner et al., 2011). Chlorambucil modifies DNA through the formation of either mono- or bifunctional adducts (Kohn, 1980). Monoadducts interfere with gene expression and promote mismatched basepairing, whereas bifunctional alkylation creates intra- and interstrand crosslinks that inhibit DNA synthesis and induce DSBs (Hemminki and Ludlum, 1984; Kohn et al., 1987). Thus exposure to chlorambucil leads to apoptotic cell death via the accumulation of extensive DNA damage (Hansson et al., 1987). The drug resistance and toxic effects associated with chlorambucil are serious impediments of therapeutic efficacy. In terms of drug resistance, sensitivity to chlorambucil is tempered by DSB repair mechanisms that are often upregulated in common cancer tumors (Mao et al., 2009; Li et al., 2012).

DSBs are life-threatening lesions whose repair is promoted by an intricate network of multiple DNA repair pathways. The MRE11-RAD50-NBS1(MRN) complex is essential for repair of

ABBREVIATIONS: ATM, ataxia-telangiectasia mutated; CDDP, cisplatin; CK2, casein kinase 2; Ctr1, copper transporter 1; DMF, $N, N{ }^{\prime}$-dimethylformamide; DMSO, dimethylsulfoxide; DSB, double-strand break; ESI-MS, electrospray ionization mass spectrometry; FBS, fetal bovine serum; $\mathrm{H}_{2} \mathrm{DCFDA}$, 2',7'-dichlorodihydrofluorescein diacetate; HR, homologous recombination; PBS, phosphate-buffer solution; MRN, MRE11-RAD50-NBS1; ROS, reactive oxygen species; TBTU, O-(benzotriazol-1-yl)- $N, N, N^{\prime}, N^{\prime}$-tetramethyluronium tetrafluoroborate. 
<smiles>N[P+]1(N)OC(=O)C2(CC(=O)C2)C(=O)O1</smiles>

DN604<smiles>O=C1CC2(C1)N[Pb]1(N[C@H]3CCCC[C@H]3N1)OC2=O</smiles>

DN603

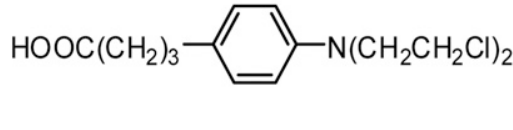

Chlorambucil<smiles>CC(=O)OP1(N)(N)OC(=O)C2(CC(=O)C2)C(=O)O1</smiles><smiles></smiles><smiles>NP(N)(Cl)(OC(=O)C(Cl)Cl)OC(=O)C(Cl)Cl</smiles>

Mitaplatin<smiles>CC(=O)Oc1ccccc1C(=O)O[P+](N)(N)(Cl)(Cl)Cl</smiles>

Asplatin

Fig. 1. Chemical structures of mentioned compounds and Pt(IV) complexes.

DSBs and stalled replication forks (von Morgen et al., 2017). MRE11, NBS1, and RAD50 form the MRN complex that allows recognition of DSBs, activates two major DDR kinases, ataxiatelangiectasia-mutated (ATM) and ataxia-telangiectasia- and Rad3-related, stabilizes ends of broken DNA, and facilitates DNA repair by homologous recombination (HR) and nonhomologous end-joining (Williams et al., 2010; Cannavo and Cejka, 2014). Therefore, severe DNA damage repair-induced drug resistance could be destructed by the inhibitors of MRNmediated DSB repair. Based on that, the approach of combing drugs with the inhibition of DSB repair in a molecule may have the potential superiority to reverse drug resistance.

The octahedral Pt(IV) complex with two additional coordination sites, exhibiting kinetic inertness and high accumulation in tumor tissues, is exploited for administration with few side effects, which have been considered to mitigate the limitations of corresponding Pt(II)-based drugs. As the first bifunctional Pt(IV) complex with two dichloroacetate moieties in the axial positions, mitaplatin was found to attack nuclear DNA and mitochondria to heighten cancer cell apoptosis (Dhar et al., 2011). Moreover, Platin-A, a hybrid of Pt(IV)aspirin, was designed to release aspirin, which exhibited anticancer and anti-inflammatory features better than the monotherapy (Fig. 1, bottom) (Pathak et al., 2014). Although the known Pt(IV) complexes showed superior ability to reverse platinum resistance via other possible mechanisms (Chen et al., 2017), specific DSB repair pathways that play an important role in the platinum resistance response have not been studied. Hence, multitargeted Pt(IV) hybrids that could suppress DSB repair response are most promising to overcome the resistance of some Pt(II) drugs. Due to the multiple biologic functions of chlorambucil, it is rational to design hybrid compounds by conjugating a chlorambucil unit into a Pt(IV) complex so as to introduce the anticancer activity of chlorambucil and reduce the toxicity of $\mathrm{Pt}(\mathrm{II})$ complexes. In this paper, two novel Pt(IV) hybrids containing a chlorambucil unit in the axial position were investigated for their effects on cisplatin-resistant cancer cells via inhibiting DSBs response-mediated pathway. In our assumption, the new compounds could not only show enhanced antitumor property but also exhibit the resistance prevention via acting on multiple targets.

\section{Materials and Methods}

Materials and General Measurements. Common chemicals and solvents were purchased from Sinopharm Chemical Reagent Co.(Beijing, China) DN604 (1) and DN603 (2) were prepared as described previously (Zhao et al., 2014). Elemental analyses for C, H, and N were 
done on a Vario MICRO CHNOS Elemental Analyzer (Elementar, Fulda, Germany). ${ }^{1} \mathrm{H}$ and ${ }^{13} \mathrm{C}$ spectra of the corresponding platinum(IV) complexes were measured in $\mathrm{d}_{6}$-DMSO with a Bruker $300 \mathrm{MHz}$ spectrometer (Bruker, Germany), and chemical shifts were internally referenced to solvent signals. Electrospray ionization mass spectrometry (ESI-MS) was measured on an Agilent 6224 TOF LC/MS instrument. Fluorescence spectra were recorded on a Hitachi F-4600 fluorescence spectrometer (Tokyo, Japan) using a 1-cm path-length cuvette. Inductively coupled plasma-optical emission spectrometer (Optima 2100DV; PE Waltham, MA) was determined to detect platinum contents. Distilled water was purified by passage through a Millipore Milli-Q Biocel (Billerica, MA) water purification system (18.2 MV) equipped with a $0.22 \mu \mathrm{m}$ filter. Analyses were performed on a Thermo 96-well plate microplate absorbance reader (Thermo, Waltham, MA). Flow cytometry studies were performed on a BD LSRII flow cytometer equipped with Cell-Quest software from BD Biosciences (San Diego, CA). Confocal images were recorded in an Olympus FV1000 (Tokyo, Japan) confocal microscope.

Procedure for Synthesis of 3. $\mathrm{N}$-Chlorosuccinimide $(29.38 \mathrm{mg}$, $0.22 \mathrm{mmol}$ ) dissolved in $14 \mathrm{ml}$ of water was added to a suspension of 1 (84.75 mg, $0.22 \mathrm{mmol}$ ) in $6 \mathrm{ml}$ of water. The reaction was stirred at room temperature for 3 hours in the dark. The solid residue was removed by centrifugation, and the solution was evaporated to dryness to get a pale yellow solid that was washed with ethanol and diethylether. Yield: $78.96 \mathrm{mg}(82 \%) .{ }^{1} \mathrm{H}$ NMR (300 MHz, DMSO-d $\left.\mathrm{d}_{6}\right): \delta$ $2.95(\mathrm{~s}, 1 \mathrm{H}), 3.45(\mathrm{~s}, 2 \mathrm{H}), 3.49(\mathrm{~s}, 2 \mathrm{H}), 5.90-5.72(\mathrm{~m}, 6 \mathrm{H}) \mathrm{ppm} .{ }^{13} \mathrm{C} \mathrm{NMR}$ (75 MHz, DMSO-d $\mathrm{d}_{6}$ ): $\delta 45.62,59.67,60.21,176.37,204.40 \mathrm{ppm}$.

Procedure for Synthesis of 4. $N$-Chlorosuccinimide $(29.38 \mathrm{mg}$, $0.22 \mathrm{mmol}$ ) dissolved in $14 \mathrm{ml}$ of water was added to a suspension of 2 (102.38 mg, $0.22 \mathrm{mmol}$ ) in $6 \mathrm{ml}$ of water. The reaction was stirred at room temperature for 3 hours in the dark. The solid residue was removed by centrifugation, and the solution was evaporated to dryness to get a pale yellow solid that was washed with ethanol and diethylether. Yield: $96.83 \mathrm{mg}(85 \%) .{ }^{1} \mathrm{H}$ NMR (300 MHz, DMSO- $\left.\mathrm{d}_{6}\right): \delta$ $1.00-1.12(\mathrm{~m}, 2 \mathrm{H}), 1.41(\mathrm{dd}, J=22.4,11.2 \mathrm{~Hz}, 1 \mathrm{H}), 1.47(\mathrm{~d}, J=7.9 \mathrm{~Hz}$, $3 \mathrm{H}), 1.96(\mathrm{~d}, J=10.6 \mathrm{~Hz}, 1 \mathrm{H}), 2.02(\mathrm{~d}, J=11.2 \mathrm{~Hz}, 1 \mathrm{H}), 2.59(\mathrm{dd}, J=22.3$, $11.8 \mathrm{~Hz}, 2 \mathrm{H}), 2.82(\mathrm{~s}, 1 \mathrm{H}), 3.43(\mathrm{~d}, J=5.3 \mathrm{~Hz}, 2 \mathrm{H}), 3.48(\mathrm{~d}, J=5.1 \mathrm{~Hz}, 2 \mathrm{H})$, $7.04(\mathrm{t}, J=9.5 \mathrm{~Hz}, 1 \mathrm{H}), 7.18(\mathrm{t}, J=9.4 \mathrm{~Hz}, 1 \mathrm{H}), 7.58(\mathrm{~d}, J=6.3 \mathrm{~Hz}, 1 \mathrm{H})$, $7.86(\mathrm{~d}, J=6.8 \mathrm{~Hz}, 1 \mathrm{H}) \mathrm{ppm} .{ }^{13} \mathrm{C} \mathrm{NMR}\left(75 \mathrm{MHz}, \mathrm{DMSO}-\mathrm{d}_{6}\right): \delta 23.69$, 23.84, 30.35, 30.80, 45.68, 59.97, 60.07, 60.99, 61.77, 176.45, 176.55, $204.30 \mathrm{ppm}$.

Procedure for Synthesis of 5. A solution of TBTU $(96.33 \mathrm{mg}$, $0.30 \mathrm{mmol}$ ) and chlorambucil (60.84 $\mathrm{mg}, 0.20 \mathrm{mmol})$ in $10 \mathrm{ml}$ of DMF dry was stirred at room temperature under $\mathrm{N}_{2}$ atmosphere. After 10 minutes, trimethylamine $(41.73 \mu \mathrm{l}, 0.30 \mathrm{mmol})$ was added, and reaction was stirred for 15 minutes. $3(87.54 \mathrm{mg}, 0.20 \mathrm{mmol})$ was then added, and the reaction mixture was stirred at room temperature for 12 hours. The solvent was then removed by evaporation under reduced pressure. The product was isolated by direct-phase chromatography using silica as stationary phase and a solution of 15:1 dichloromethane/methanol as eluent. Yield: $65.15 \mathrm{mg}(45 \%)$. ESI-MS: $m / z[\mathrm{M}-\mathrm{H}]^{-}=$ 722.05. ${ }^{1} \mathrm{H}$ NMR $\left(300 \mathrm{MHz}, \mathrm{DMSO}-\mathrm{d}_{6}\right): \delta 1.67-1.72(2 \mathrm{H}, \mathrm{m}), 2.21-2.26$ $(2 \mathrm{H}, \mathrm{m}), 2.42-2.45(2 \mathrm{H}, \mathrm{m}), 3.49(4 \mathrm{H}, \mathrm{s}), 3.68(8 \mathrm{H}, \mathrm{s}), 6.28(6 \mathrm{H}, \mathrm{m})$, 6.63-6.66 (2H, d), 6.99-7.02(2H, d) ppm. ${ }^{13} \mathrm{C}$ NMR (75 MHz, DMSO$\left.\mathrm{d}_{6}\right): \delta 28.02,33.91,35.34,41.66,46.22,52.72,60.02,60.16,112.32$, $129.92,130.51,144.86,176.29,176.42,179.43,204.15 \mathrm{ppm}$. (\%) for $\mathrm{C}_{20} \mathrm{H}_{28} \mathrm{Cl}_{3} \mathrm{~N}_{3} \mathrm{O}_{7}$ Pt: C 33.18, H 3.90, N 5.80. Found: C 32.89, H 4.15, N 5.57 .

Procedure for Synthesis of 6. A solution of TBTU (96.33 mg, $0.30 \mathrm{mmol}$ ) and chlorambucil $(60.84 \mathrm{mg}, 0.20 \mathrm{mmol})$ in $10 \mathrm{ml}$ of DMF dry was stirred at room temperature under $\mathrm{N}_{2}$ atmosphere. After 10 minutes, trimethylamine $(41.73 \mu \mathrm{l}, 0.30 \mathrm{mmol})$ was added and reaction was stirred for 15 minutes. $4(87.54 \mathrm{mg}, 0.20 \mathrm{mmol})$ was then added and the reaction mixture was stirred at room temperature for 12 hours. The solvent was then removed by evaporation under reduced pressure. The product was isolated by direct-phase chromatography using silica as stationary phase and a solution of 15:1 dichloromethane/methanol as eluent. Yield: $77.18 \mathrm{mg}$ (48\%). ESI-MS: $\mathrm{m} / z$
$[\mathrm{M}-\mathrm{H}]^{-}=802.12 .{ }^{1} \mathrm{H}$ NMR $\left(300 \mathrm{MHz}, \mathrm{DMSO}-\mathrm{d}_{6}\right): \delta 1.07-1.51(6 \mathrm{H}$, $\mathrm{m}), 1.70-1.74(2 \mathrm{H}, \mathrm{m}), 1.98-2.11(2 \mathrm{H}, \mathrm{m}), 2.25-2.30(2 \mathrm{H}, \mathrm{m}), 2.42-2.45$ $(2 \mathrm{H}, \mathrm{m}), 2.56-2.68(2 \mathrm{H}, \mathrm{m}), 3.38(2 \mathrm{H}, \mathrm{s}), 3.52(2 \mathrm{H}, \mathrm{s}), 3.69(8 \mathrm{H}, \mathrm{s})$, 6.63-6.65 (2H, d), 6.99-7.02 (2H, d), 7.97-8.55 (4H, m) ppm. ${ }^{13} \mathrm{C} \mathrm{NMR}$ $\left(75 \mathrm{MHz}, \mathrm{DMSO}-\mathrm{d}_{6}\right): \delta 23.94,24.04,27.08,30.98,31.37,33.82,36.41$, 41.65, 46.29, 52.72, 59.12, 60.70, 61.99, 62.21, 112.36, 129.83, 130.35, $144.90,176.51,176.59,180.55,203.94 \mathrm{ppm}$. (\%) for $\mathrm{C}_{26} \mathrm{H}_{36} \mathrm{Cl}_{3} \mathrm{~N}_{3} \mathrm{O}_{7} \mathrm{Pt}$ : C 38.84, H 4.51, N 5.23. Found: C 38.65, H 4.60, N 4.99.

Cell Culture. Cisplatin-sensitive SGC-7901 and A549 cancer cell lines, and cisplatin-resistant SGC-7901/CDDP and A549/CDDP cancer lines as well as normal HUVEC cell line were purchased from the Cell Bank of Shanghai Institute of Cell Biology. HUVEC cells were cultured at $37^{\circ} \mathrm{C}$ in $5 \% \mathrm{CO}_{2}$ with DMEM supplemented with $10 \%$ fetal bovine serum (FBS) (Hyclone; Lifescience, East Lansing, MI), $100 \mathrm{U} / \mathrm{ml}$ benzyl penicillin, and $100 \mathrm{mg} / \mathrm{ml}$ streptomycin (Beyotime, Nantong, China), while SGC-7901 and A549 cancer cells were cultured at $37^{\circ} \mathrm{C}$ in $5 \% \mathrm{CO}_{2}$ with RPMI-1640 supplemented with $10 \% \mathrm{FBS}$ and $100 \mathrm{U} / \mathrm{ml}$ benzyl penicillin and $100 \mathrm{mg} / \mathrm{ml}$ streptomycin. Moreover, SGC-7901/CDDP and A549/CDDP cancer cells were cultured and screened in RPMI-1640 supplemented with $10 \%$ FBS, $100 \mathrm{U} / \mathrm{ml}$ benzyl penicillin, $100 \mathrm{mg} / \mathrm{ml}$ streptomycin, and $800 \mathrm{ng} / \mathrm{ml}$ cisplatin before use. Cells were passed every 2 days and restarted from frozen stocks upon reaching pass number 20 .

In Vitro Cell Viability Assay. Cytotoxicity profiles of the tested compounds against different cell lines were evaluated by the MTT assay. Cells were plated at density of $10^{5} / \mathrm{ml}$ per well in 96 -well plates. After overnight growth, cells were exposed to medium containing the tested compounds separately at varying concentrations and incubated for 72 hours at $37^{\circ} \mathrm{C}$. Then the cell viability was determined by the MTT method according to previous description (Chen et al., 2012).

Reactions of Compound 5 with DNA. Herring sperm DNA was dissolved in $10 \mathrm{mM}$ phosphate buffer (pH 7.4) containing $10 \mathrm{mM}$ $\mathrm{NaClO}_{4}$. The DNA concentration was determined by UV-vis spectra at $260 \mathrm{~nm}$ with an extinction coefficient of $6600 \mathrm{M}^{-1}$. The mixture of DNA with platinum compounds were incubated at $37^{\circ} \mathrm{C}$ in the dark. The fluorescence was measured in $0.4 \mathrm{M} \mathrm{NaCl}$ to avoid the second fixation site of EtBr to DNA. EtBr $(0.04 \mathrm{mg} / \mathrm{ml})$ was added to the $0.01 \mathrm{mg} / \mathrm{ml}$ DNA solution before the fluorescence measurement. Ascorbic acid was added for the reduction of compound 5. Fluorescence spectra were recorded under the following conditions: scan speed $2000 \mathrm{~nm} \cdot \mathrm{min}^{-1}$; excitation slit width was $5 \mathrm{~nm}$, and emission slit width was $10 \mathrm{~nm}$. The excitation and emission wavelength was 530 and $592 \mathrm{~nm}$, respectively.

Cellular Platinum Uptake and DNA Platination Assay. The cellular uptakes of cisplatin and compound $\mathbf{5}$ were measured on A549 and A549/CDDP cells. The cells were seeded in six-well plates overnight and then incubated with $15 \mu \mathrm{M}$ cisplatin and compound 5 at $37^{\circ} \mathrm{C}$ (unobstructed interaction) or at $4^{\circ} \mathrm{C}$ (interaction partially inhibited) in standard culture conditions. After 4 hours, the cells were washed with PBS buffer ( $\mathrm{pH}$ 7.4) for three times and harvested by trypsinization. After resuspension in PBS, the pellet was washed with PBS and collected per centrifugation (5910R; Eppendorf, Hamburg, Germany) at $500 \mathrm{~g}$ for 5 minutes at $4^{\circ} \mathrm{C}$. The organelles were then isolated via differential centrifugation. All cellular compartments (mitochondria, lysosomes, and nucleus) were isolated from A549 and A549/CDDP cells for direct comparative purposes. The supernatant phases discarded during the isolation of nuclei, lysosomes, and mitochondria procedures were collected and formed the "residual" fraction. An aliquot of crude lysate after homogenization, nuclear, mitochondrial (pellet lysedvia freeze and thaw cycles followed by 20-minute incubation in ultrasonic bath), lysosomal, and residual fraction was used for each protein quantification using the Bradford method (Siddiqui-Jain et al., 2010). The harvested cells were concentrated and digested by nitric acid for the Inductively coupled plasma mass spectrometry (ICP-MS) measurement. The cell numbers were counted before they were digested. For the measurement of Pt concentration in cellular DNA in A549 and A549/CDDP cells, DNA was isolated by applying Genomic DNA Mini Preparation Kit 
(Beyotime Shanghai, China), and Pt content in DNA was analyzed by ICP.

Apoptosis Assessment. The apoptosis induced by compound 5 was detected by Annexin V-FITC apoptosis detection kit according to the manufacturer's protocol (Keygen Biotech, Jiangsu, China). Briefly, cells were treated with $15 \mu \mathrm{M}$ chlorambucil, cisplatin, DN604, and compound $\mathbf{5}$, respectively, for 24 hours at $37^{\circ} \mathrm{C}$. Then the cells were collected, resuspended in binding buffer ( $\mathrm{pH} 7.5,10 \mathrm{mM}$ HEPES, $2.5 \mathrm{mM} \mathrm{CaCl}_{2}$, and $140 \mathrm{mM} \mathrm{NaCl}$ ), and incubated with Annexin V-FITC and then PI for 10 minutes in the dark at room temperature, cells were analyzed by flow cytometry (FACSCalibur, Becton Dickinson Franklin Lakes, NJ) and a computer station running Cell-Quest software (BD Biosciences).

Analysis of Caspase-3 Activation. For the quantification of activation of caspase- 3 in cancer cells, $5 \times 10^{5}$ cancer cells were seeded in a $60-\mathrm{mm}$ dish and allowed to adhere for 1 day. The cells were incubated with cisplatin, DN604, and compound 5 at a concentration of $15 \mu \mathrm{M}$ for 24 hours to induce the activation of caspase-3. As a reference control, the cells were incubated only with fresh media at $37^{\circ} \mathrm{C}$. Then, the cells were washed with PBS to eliminate the remaining drugs and harvested using trypsin-EDTA. All the groups of cells were collected into microtubes after incubation with $300 \mathrm{ml}$ media containing $1 \mathrm{ml}$ of FITCDEVD-FMK [Caspase 3(active) FITC Staining Kit (ab65613)] for 1 hour at $37^{\circ} \mathrm{C}$ under $5 \% \mathrm{CO}_{2}$. Subsequently, centrifugation of the cells was performed to collect cell pellets and washed two times with washing buffer. Each group of cells was resuspended with $300 \mathrm{ml}$ of the washing buffer and transferred $100 \mathrm{ml}$ per well in a microtiter plate reader. The quantification of caspase-3 was evaluated as relative fluorescence unit using fluorophotometer (Max Gemini EM, SoftMax Pro 5; Molecular Devices Corp., Sunnyvale, CA) at an emission wavelength of $535 \mathrm{~nm}$ after excitation at $485 \mathrm{~nm}$. The statistical significance was evaluated with one-way analysis of variance test using GraphPad Prism 4 software.

Colony Formation Assay. Cells were trypsinized and plated at a density of 500 per plate. Fourteen days later, $15 \mu \mathrm{M}$ chlorambucil, cisplatin, DN604, and compound $\mathbf{5}$ in cell culture medium were added to the plates, and cells were incubated for an additional 7 days. Cells were then fixed with $3 \%$ paraformaldehyde, stained with crystal violet, and imaged with a light microscope. The experiment was performed in triplicate. The number of colonies, defined as containing $>50$ cells, was counted.

Cell-Cycle Analysis. Cell cycle was analyzed by flow cytometry as described previously (Chen et al., 2010). Data were analyzed with FlowJo software (TreeStar, Inc., Mesa, AZ).

Analysis of Intracellular $\mathbf{K}^{+}$Leakage. A549 and A549/CDDP cancer cells were incubated with $15 \mu \mathrm{M}$ chlorambucil, cisplatin, $\mathrm{DN604}$, and compound 5 at $37^{\circ} \mathrm{C}$ for 4 hours. After every 1-hour interval during incubation, the suspensions were collected, and supernatants were transported. Extracellular $\mathrm{K}^{+}$concentration was measured using anion selective electrode meter (Orion Star A214; Thermo Scientific, Singapore). The $\mathrm{K}^{+}$concentration was calculated using the following formula: $\mathrm{K}^{+}$leakage $(\%)=\left(\left[\mathrm{K}^{+}\right]-\left[\mathrm{K}^{+}\right]_{0}\right) /\left(\left[\mathrm{K}^{+}\right]_{t}-\right.$ $\left.\left[\mathrm{K}^{+}\right]_{0}\right) \times 100$, where $\left[\mathrm{K}^{+}\right]$is the $\mathrm{K}^{+}$leakage induced by each compound and $\left[\mathrm{K}^{+}\right]_{0}$ and $\left[\mathrm{K}^{+}\right]_{t}$ are the $\mathrm{K}^{+}$leakage without the compounds and with sonication, respectively. Here, sonicated cells (1 minute, 60 amplitude) were used to determine $100 \% \mathrm{~K}^{+}$leakage (Arduino et al., 2009; Yannopoulos et al., 2015).

Analysis of Cytosolic and Mitochondrial $\mathbf{C a}^{2+}$ Levels. A549 and A549/CDDP cancer cells were incubated with $15 \mu \mathrm{M}$ chlorambucil, cisplatin, DN604, and compound 5 at $37^{\circ} \mathrm{C}$ for 4 hours. After incubation, the cells were washed three times with Krebs buffer (132 mM NaCl, $4 \mathrm{mM} \mathrm{KCl}, 1.4 \mathrm{mM} \mathrm{MgCl}$, $6 \mathrm{mM}$ glucose, $10 \mathrm{mM}$ HEPES, $10 \mathrm{mM} \mathrm{NaHCO}$, and $1 \mathrm{mM} \mathrm{CaCl}_{2}, \mathrm{pH}$ 7.2) with $0.01 \%$ Pluronic F-127 (Molecular Probes, Eugene, OR) and 1\% bovine serum albumin was added to the cells. The suspensions were incubated with Rhod-2 AM $(10 \mu \mathrm{M})$ or Fura-2 AM $(5 \mu \mathrm{M})$ (Molecular Probes) at $37^{\circ} \mathrm{C}$ for 30 minutes and then washed three times with calcium-free Krebs buffer. The fluorescence intensities of Fura-2 AM (excitation- $335 \mathrm{~nm}$, emission-505 nm) and Rhod-2 AM (excitation-550 nm, emission-580 nm) were analyzed using a spectrofluorophotometer (Shimadzu RF-5301PC; Shimadzu, Kyoto, Japan) (Alonso-Monge et al., 2009; Valipour et al., 2015).

Mitochondrial Transmembrane Potential $\left(\Delta \Psi_{m}\right)$ Assessment. The electrical potential difference across inner mitochondrial membrane $\left(\Delta \Psi_{\mathrm{m}}\right)$ was monitored using the $\Delta \Psi_{\mathrm{m}}$-specific fluorescent probe JC-1 (Molecular Probes Inc.), a sensitive fluorescent dye. Briefly, the cancer cells treated with $15 \mu \mathrm{M}$ of cisplatin, chlorambucil, DN604, or compound 5 for 24 hours were harvested with ice-cold PBS and resuspended in RPMI-1640 medium at a density of $0.5 \times 10^{6}$ cells $/ \mathrm{ml}$ and then the cells were permeabilized with $0.3 \%$ Triton X-100, washed with ice-cold PBS, incubated with $10 \mu \mathrm{M}$ JC-1 for 15 minutes at $37^{\circ} \mathrm{C}$ in the dark and observed under a fluorescence microscope (Olympus IX51, Olympus). Red fluorescence is attributable to a potential-dependent aggregation in the mitochondria. Green fluorescence, reflecting the monomeric form of JC-1, appeared in the cytosol after mitochondrial membrane depolarization. Relative fluorescence intensities were monitored using the flow cytometry (FACSCalibur; Becton Dickinson), and analyzed by the software Modfit and Cell Quest (BD Biosciences) with settings of FL1 (green) at $530 \mathrm{~nm}$ and FL2 (red) at $585 \mathrm{~nm}$.

Measurement of ATP Production. The ATP production assay kit (Haimen, Jiangsu, China) was used to measure intracellular ATP level according to the manufacturer's instructions. In brief, cells were treated with $15 \mu \mathrm{M}$ of chlorambucil, cisplatin, DN604, and compound 5, respectively, for 12 hours, then incubated with $100 \mu \mathrm{l}$ nuclear releasing reagent for 5 minutes at $37^{\circ} \mathrm{C}$ with gentle shaking, followed by further incubation with $1 \mu$ l ATP monitoring enzyme. Detection was performed using the luminometer Orion II (Berthold DS; Bleichstr, Pforzheim, Germany).

ROS Measurement. The generation of ROS induced by compound 5 was determined with the cell-permeant fluorogenic probe 2',7'-dichlorodihydrofluorescein diacetate $\left(\mathrm{H}_{2} \mathrm{DCFDA}\right.$; Molecular Probes, Invitrogen, Darmstadt, Germany). $\mathrm{H}_{2}$ DCFDA diffuses into the cell, where it is enzymatically converted by intracellular esterases and oxidized into the high fluorescence compound DCF, which allows the determination of $\mathrm{H}_{2} \mathrm{O}_{2}$, peroxynitrite anions and peroxyl radicals. Approximately $4 \times 10^{3}$ A549 and A549/CDDP cells per well were plated on white bottom 96 -well plates in extracellular fluid (140 nM $\mathrm{NaCl}, 3 \mathrm{mM} \mathrm{KCl}, 1 \mathrm{mM} \mathrm{CaCl}_{2}, 1 \mathrm{mM} \mathrm{MgCl} 2,10 \mathrm{mM}$ HEPES, and $25 \mathrm{mM}$ glucose; $\mathrm{pH}$ 7.4). After 24-hour incubation, cells were treated with $15 \mu \mathrm{M}$ chlorambucil, cisplatin, DN604, and compound 5 for 6 hours at $37^{\circ} \mathrm{C}$. Then cells were loaded with $10 \mathrm{mM} \mathrm{H}_{2}$ DCFDA for 30 minutes at $37^{\circ} \mathrm{C}$ and $5 \% \mathrm{CO}_{2}$. Then DCF generation of cells was measured over time using a fluorometer (Fluostar BMG Labtech, Offenburg, Germany) at $492 \mathrm{~nm}$ excitation and $520 \mathrm{~nm}$ emission.

$\mathrm{H}_{2} \mathrm{O}_{2}$ Measurement. The production of $\mathrm{H}_{2} \mathrm{O}_{2}$ was determined with the Amplex Red reagent (10-acetyl-3,7-dihydroxyphenoxazine; Molecular Probes). In the presence of horseradish peroxidase, the Amplex Red reagent reacts in a 1:1 stoichiometry to produce the redfluorescent oxidation product resorufin. Consequently, resorufin generation allows the detection of the $\mathrm{H}_{2} \mathrm{O}_{2}$ released from biologic compounds. Approximately $4 \times 10^{3}$ A549 and A549/CDDP cancer cells were plated on black bottom 96 -well plates in $120 \mathrm{ml}$ of working solution containing $40 \mathrm{mM}$ Amplex Red reagent and $0.1 \mathrm{U} / \mathrm{ml}$ horseradish peroxidase and incubated in the presence of $15 \mu \mathrm{M}$ chlorambucil, cisplatin, DN604, and compound 5 for 2 hours at $37^{\circ} \mathrm{C}$. Resorufin generation was measured over time using a fluorometer (Fluostar BMG Labtech, Ortenberg, Germany) at $544 \mathrm{~nm}$ excitation and $590 \mathrm{~nm}$ emission.

Intracellular GSH Measurement. A549 and A549/CDDP cancer cells in 6-cm culture plates were treated as follows: $15 \mu \mathrm{M}$ chlorambucil, cisplatin, DN604, and compound 5. After 4 hours, medium was removed and dishes were rinsed three times with cold PBS. The cells were harvested and cell numbers were counted. Then, intracellular GSH levels were measured using a GSH test kit (KeyGen KGT006). A549 and A549/CDDP cancer cells without treatment were used as control groups. 
Comet Assay. A549 and A549/CDDP cells $\left(1 \times 10^{5}\right.$ cells $)$ treated with $15 \mu \mathrm{M}$ chlorambucil, cisplatin, DN604, and compound $\mathbf{5}$ for 24 hours were combined with molten LM Agarose (Trevigen Gaithersburg, MD) at a ratio of 1:10 (v/v) and were immediately pipetted onto Comet slide (Trevigen). Slides were incubated at $4^{\circ} \mathrm{C}$ in the dark for 10 minutes, then immersed in prechilled Lysis buffer and incubated at $4^{\circ} \mathrm{C}$ for 30 minutes. Slides were immersed in alkaline unwinding solution, $\mathrm{pH}>13$ ( $200 \mathrm{mM} \mathrm{NaOH}, 1 \mathrm{mM}$ EDTA), for 20 minutes at room temperature in the dark. Electrophoresis was done at $21 \mathrm{~V}$ for 30 minutes using alkaline electrophoresis solution $(200 \mathrm{mM} \mathrm{NaOH}$, $1 \mathrm{mM}$ EDTA). The slides were washed twice in water for 5 minutes and once in $70 \% \mathrm{EtOH}$ for 5 minutes and then dried overnight and visualized by microscopy. The cells were analyzed by Comet Assay Software Project (CASP).

Determination of DNA Lesion Frequency by Quantitative Polymerase Chain Reaction. Determination of DNA lesion frequency was determined from a published method (Fonseca et al., 2011). A total of $1 \times 10^{6} \mathrm{~A} 549$ and A549/CDDP cancer cells were treated with cisplatin and compound $5(15 \mu \mathrm{M})$ for 4 hours. Then DNA was isolated from frozen cell pellets using the Qiagen Genomic Tip and quantified via PicoGreen dye (Invitrogen). Quantitative amplification of the $8.9-\mathrm{kb}$ mitochondrial segment and the $17.7 \mathrm{~kb} \beta$-globin target sequence was performed using the GeneAmp XL PCR kit (PerkinElmer Waltham, MA). Lesion frequency at a given dose, $D$, was calculated as $D=-\ln A_{\mathrm{D}} / A_{\mathrm{C}}$, where $A_{\mathrm{D}}$ is the amplification at the dose and $A_{\mathrm{C}}$ is the level of amplification in untreated controls.

Immunofluorescence and Foci Detection. Briefly, A549 and A549/CDDP cells were grown to confluence in $35-\mathrm{mm}$ sterile dishes with $0.17-\mathrm{mm}$ glass bottom for 24 hours at $37^{\circ} \mathrm{C}$. After treatment of $15 \mu \mathrm{M}$ chlorambucil, cisplatin, DN604, and compound 5, respectively, for 24 hours, cells were washed with PBS, fixed in $4 \%$ paraformaladehyde/PBS for 0.5 hour, and permeabilized with PT-5 solution [0.3\% Triton X-100 in PBS] for 30 minutes at $4^{\circ} \mathrm{C}$. The cells were blocked by incubating with PTB-5 [0.5\% bovine serum albumin in PBS] for 1 hour at room temperature. Dishes were then incubated with primary antibody (1:500) overnight at $4^{\circ} \mathrm{C}$. Cells were stained with secondary antibody conjugated with Alexa 488 (1:100; Invitrogen, Carlsbad, CA) and the DNA counterstained with $1 \mathrm{mM}$ DAPI (Invitrogen). Microscopy was performed on a Leica TCS NT confocal scanner equipped with an ArKr-Laser on the Leica DM IRBE inverted microscope (lens: HCX PlanApo 63x oil/NA1.32). Confocal images were displayed as maximum projections and assembled in Adobe Photoshop 7.0. Slides for the foci detection were produced and counted in 120 cells per slide. The results could be recorded as both foci values per cell and the percentage of cells with 4 or $\geq 10$ foci.

Western Blot Analysis. After the treatment of the indicated concentration of $15 \mu \mathrm{M}$ cisplatin, DN604, and compound 5 for 24 hours, A549 and A549/CDDP cells were collected and lysed in lysis buffer [100 mM Tris-Cl, pH 6.8, 4\% (m/v) sodium dodecylsulfonate, $20 \%(\mathrm{v} / \mathrm{v})$ glycerol, $200 \mathrm{mM} \beta$-mercaptoethanol, $1 \mathrm{mM}$ phenylmethylsulfonyl fluoride, and $1 \mathrm{~g} / \mathrm{ml}$ aprotinin]. Lysates were centrifuged at $12,000 \mathrm{~g}$ for 0.5 hour at $4^{\circ} \mathrm{C}$. The concentrations of total proteins were measured using the BCA assay method with Varioskan spectrofluorometer and spectrophotometer (Thermo) at $562 \mathrm{~nm}$. Protein $(20-100 \mu \mathrm{g}$ ) prepared from the indicated cells was loaded per lane and electrophoresed in $8 \%$ or $10 \%$ sodium dodecyl sulfate polyacrylamide gel electrophoresis (SDS-PAGE) and then transferred onto polyvinylidene difluoride Immobilon-P membrane (Bio-Rad, Hercules, CA) using a transblot apparatus (Bio-Rad). The membranes were blocked with $5 \%(\mathrm{w} / \mathrm{v})$ nonfat milk at 0.5 hour at $37^{\circ} \mathrm{C}$, followed by overnight incubation at $4^{\circ} \mathrm{C}$ with primary antibodies diluted in Phosphate buffered solution with Tween-20 (PBST). After washing with PBST, the membranes were incubated for 1 hour with an IRDye $\times 800$ conjugated secondary antibody diluted 1:20,000 in PBST, and the labeled proteins were detected with an Odyssey Scanning System (Li-COR, Lincoln, NE).

CK2 Activity Assay. The CK2 activity was detected with the CK2 assay kit treated with $15 \mu \mathrm{M}$ cisplatin, DN604 and compound 5, respectively, according to manufacturer's instruction (Chen et al., 2012).
In Vivo Antitumor Efficacy of Compound 5. Thirty-five nude mice (BALB/c) with body weight range from 18 to $22 \mathrm{~g}$ were supplied by Shanghai Laboratory Animal Center, China Academy of Sciences. Experimental protocols were in accordance with National Institutes of Health regulations and approved by the Institutional Animal Care and Use Committee. All animals were randomly divided into five groups. The cisplatin-resistant A549/CDDP single-cell suspension in PBS $\left(1 \times 10^{7}\right.$ cells per mouse $)$ was injected subcutaneously into the right oxter of nude mice. When tumor grew to a size of $80-150 \mathrm{~mm}^{3}$ at 12 days, the mice were administrated via cisplatin (dosed intravenously at $5 \mathrm{mg} / \mathrm{kg}$ twice a week), chlorambucil (dosed intravenously at $5 \mathrm{mg} / \mathrm{kg}$ once every 3 days), DN604 (dosed intravenously at $5 \mathrm{mg} / \mathrm{kg}$ once every 3 days), compound 5 (dosed intravenously at $5 \mathrm{mg} / \mathrm{kg}$ once every 3 days). The control group was administered glucose. The tumor growth was monitored by measuring the perpendicular diameter of the tumor using calipers every 2 days and calculated according to the formula:

$$
\text { Tumor volume }\left(\mathrm{mm}^{3}\right)=0.5 \times \text { length } \times \text { width }^{2}
$$

Growth curves were plotted using the average tumor volume within each experimental group at the set time points. The whole group of mice was euthanized after the last treatment, then tumor weight was evaluated as the antitumor activity of the corresponding groups, and the kidneys, livers, and tumors were excised for immunohistochemistry analysis. The body weight and physical state of the mice were measured simultaneously as an indicator of systemic toxicity.

Blood Stability Test of Compound 5 with Rat Plasma. To a volume of $0.6 \mathrm{ml}$ rat plasma was added $10 \mu \mathrm{l}$ of a DMSO solution of compound $5(10 \mathrm{mM})$, resulting in a final concentration of $50 \mu \mathrm{M}$. At varying time points $(0,2,4$, and 8 hours $)$ at $37^{\circ} \mathrm{C}$, a $300-\mu l$ aliquot was removed from the incubating blood. The ICP-MS measurement was served to confirm the blood stability of compound $\mathbf{5}$ in rat plasma.

Pharmacokinetics Studies. Twenty-four Sprague-Dawley rats (240-250 g) were supplied by Shanghai Laboratory Animal Center, China Academy of Sciences. Experimental protocols were in accordance with National Institutes of Health regulations and approved by the Institutional Animal Care and Use Committee. Sprague-Dawley rats composed of half male and half female were randomly divided into two groups: 1) cisplatin (5 mg/kg) and 2) compound 5 ( $5 \mathrm{mg} / \mathrm{kg})$. Blood samples $(0.6 \mathrm{ml})$ were collected from the orbital cavity at 5 minutes followed by $0.5,1,2,4,8,12$, and 24 hours after intravenous administration, heparinized, and then centrifuged at $4000 \mathrm{rpm}$ for 20 minutes at $4^{\circ} \mathrm{C}$. The supernatant plasma was collected for measurement of Pt content using ICP-MS. The apparent plasma half-life time was calculated using a Phoenix Win Nonlin 6.3 Program (Pharsight Cooperation, St. Louis, MO).

Statistical Analysis. The data shown in the study were expressed as means \pm S.D. from at least three independent experiments, each in triplicate compounds for individual treatment or dosage. Statistical analyses were performed using an unpaired, two-tailed Student's $t$ test. All comparisons are made relative to untreated controls and significance of difference is indicated as $* P<0.05$ and $* * P<0.01$.

\section{Results}

Design and Synthesis. The synthetic route to prepare compounds 5 and $\mathbf{6}$ is depicted in Scheme 1. Chlorambucil was obtained according to a literature procedure (Fousteris et al., 2006). Meanwhile, Pt(IV) complexes 3 and 4 were synthesized through the oxidative chlorination of the corresponding $\mathrm{Pt}(\mathrm{II})$ complexes (1 or 2) with $N$-chlorosuccinimide in water (Huang et al., 2016). Finally, compounds 5 and $\mathbf{6}$ were obtained via chlorambucil coupling with the corresponding Pt(IV) intermediate in the presence of $O$-(benzotriazol-1-yl)- $N, N, N^{\prime}, N^{\prime}$ tetramethyluronium tetrafluoroborate (TBTU) as the coupling 


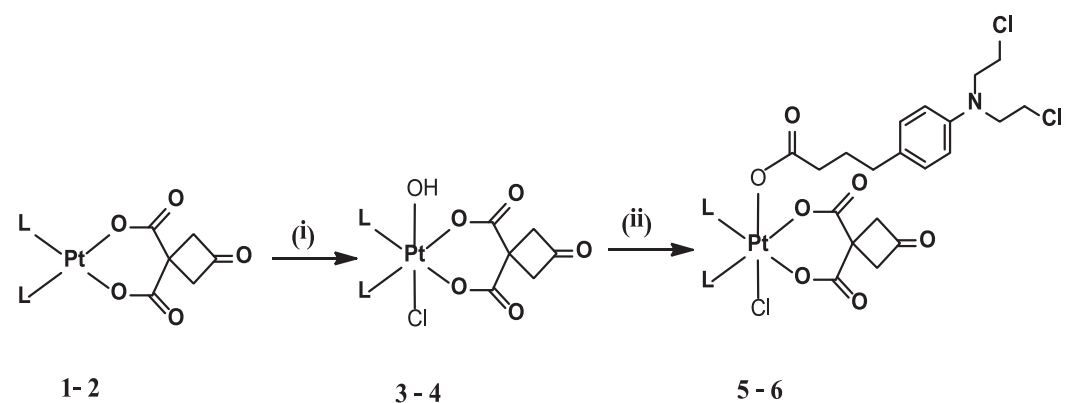

Scheme 1. Synthesis of Pt(IV) compounds 5 and 6. Reaction conditions: i) $\mathrm{N}$-chlorosuccinimide(NCS), $\mathrm{H}_{2} \mathrm{O}$, room temperature, 3 hours in the dark, and ii) chlorambucil, TBTU, TEA, DMF, $30^{\circ} \mathrm{C}$ in the dark, 24 hours.

$1,3,5: \mathrm{L}=\mathrm{NH}_{3} ; 2,4,6: \mathrm{L}, \mathrm{L}=\mathrm{DACH} ; \mathrm{DACH}=1 R, 2 R$-cyclohexanediamine

agent. The products were purified by column chromatography, and their structures were characterized by ${ }^{1} \mathrm{H}$ and ${ }^{13} \mathrm{C}$ NMR spectra together with ESI-MS spectrometer (Figs. 2 and 3).

Cytotoxicity Effects. The in vitro cytotoxicity of compounds 5 and 6 together with their Pt(II) parent complexes DN604 and DN603 was ascertained using MTT assays on a panel of human cancer cells including SGC-7901 (cisplatin-sensitive gastric cancer) and SGC-7901/CDDP (cisplatin-resistant gastric cancer), A549 (cisplatin-sensitive lung cancer) and A549/CDDP (cisplatin-resistant lung cancer), as well as human normal cell line HUVEC. Cisplatin, oxaliplatin, carboplatin, and chlorambucil were used as the positive controls. As listed in Table 1, DN604 exhibited stronger cytotoxicity than cisplatin, carboplatin, and oxaliplatin toward cisplatinresistant SGC-7901/CDDP and A549/CDDP cancer cells. The results showed that compound $\mathbf{5}$ exhibited 1.75-fold and 2.06-fold lower $\mathrm{IC}_{50}$ values toward SGC-7901/CDDP and A549/CDDP cancer cells than DN604, respectively, whereas 34.93-fold and 62.04-fold lower than chlorambucil. However, the $\mathrm{IC}_{50}$ value of compound 5 against SGC-7901 and A549 cancer cells was close to cisplatin, and those of compound 6 against all cancer cell lines were close to oxaliplatin and
A

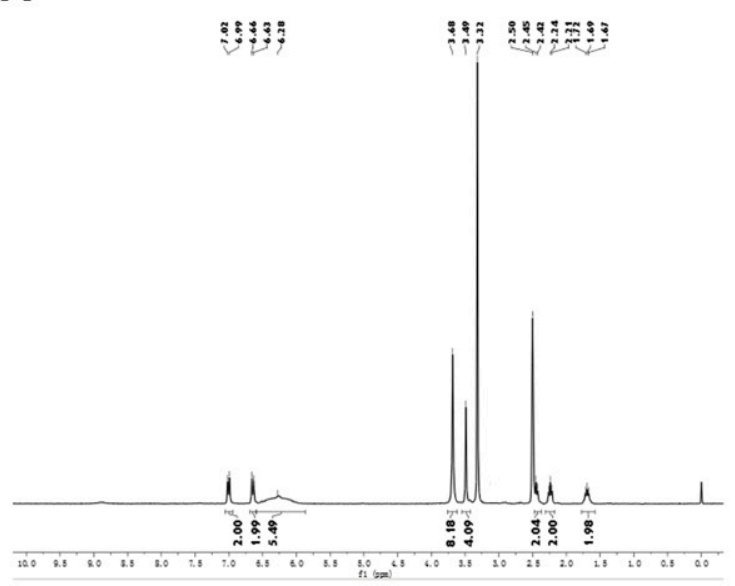

B
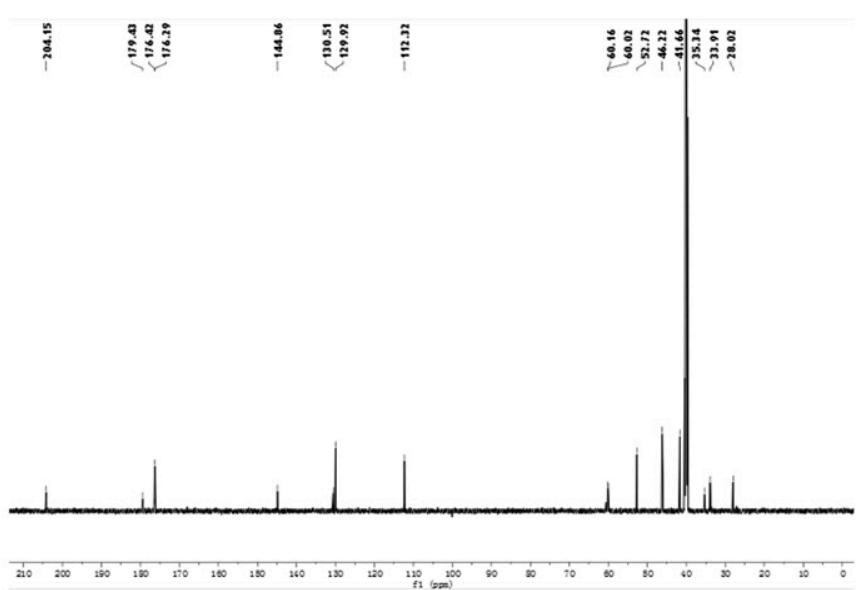

C

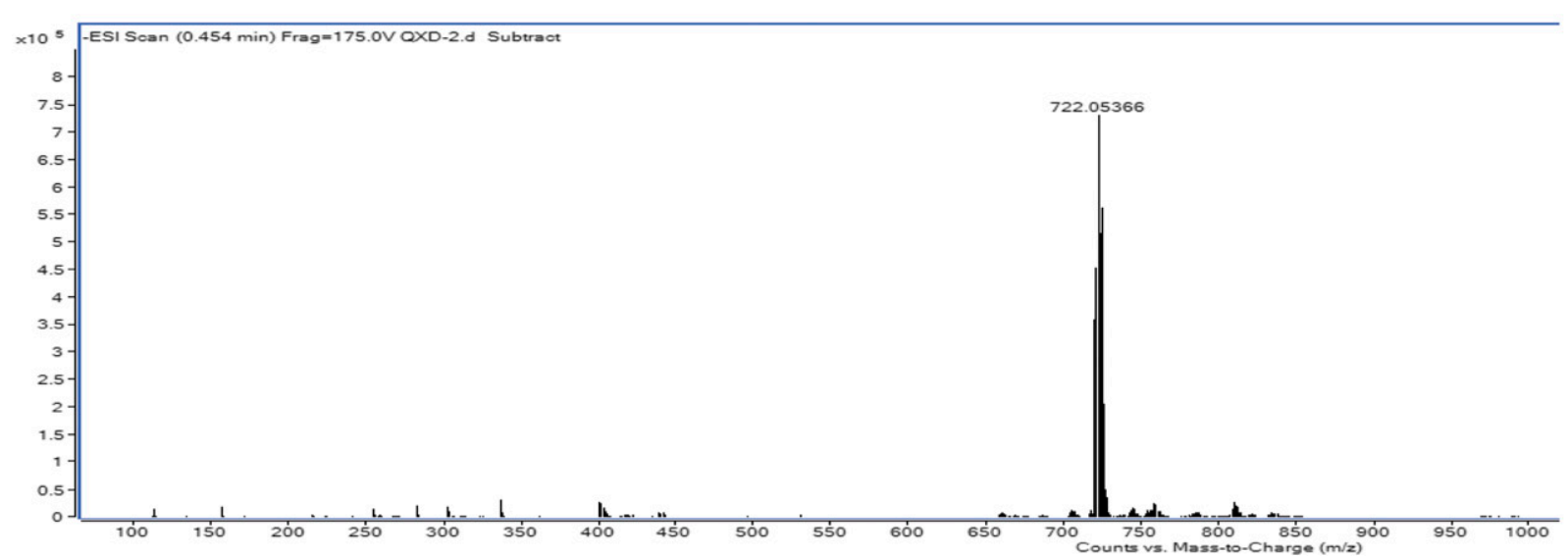

Fig. 2. ${ }^{1} \mathrm{H}(\mathrm{A}),{ }^{13} \mathrm{C}$ NMR (B), and ESI-MS (C) spectra of compound 5. 
A

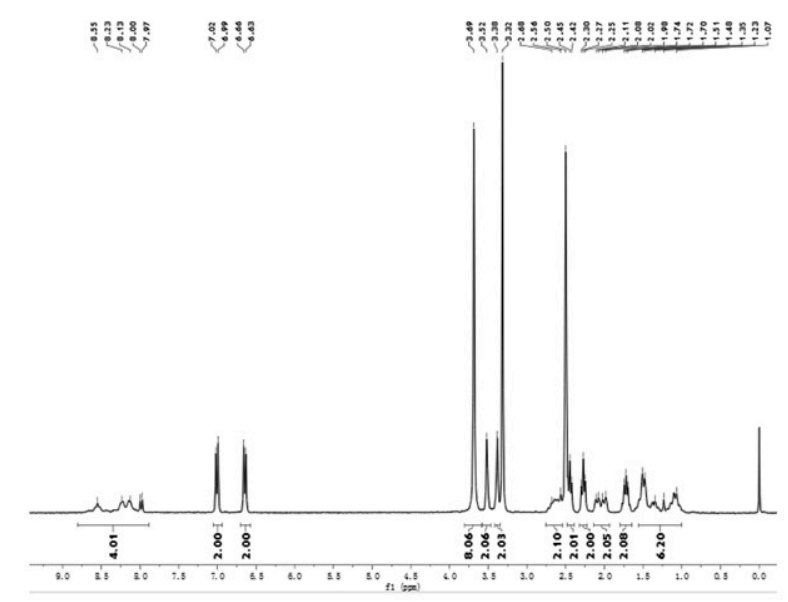

B

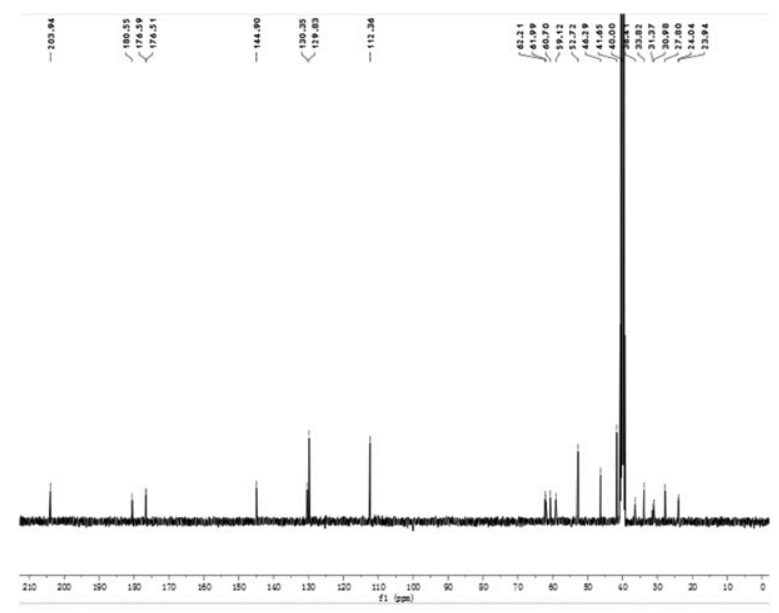

C

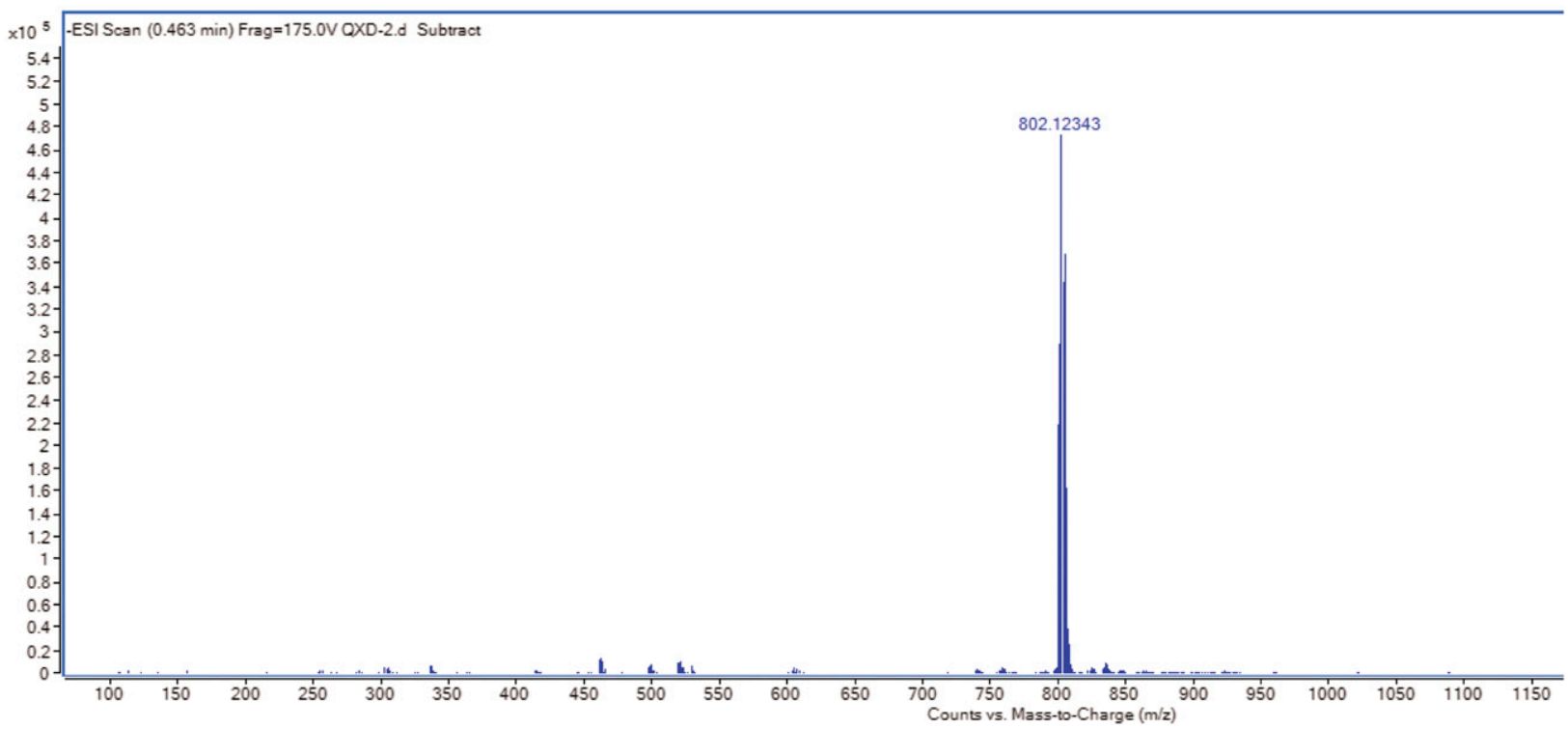

Fig. 3. ${ }^{1} \mathrm{H}(\mathrm{A}),{ }^{13} \mathrm{C}$ NMR (B) and ESI-MS (C) spectra of compound 6 .

DN603. Notably, compound 5 exhibited a greater cytotoxic activity than its parent compounds in the test of cisplatinresistant cancer cells. Such results proved that compound $\mathbf{5}$ has the potential to reverse cisplatin resistance of SGC-7901/CDDP and A549/CDDP cancer cells via reducing the drug resistance factor from 7.09 (cisplatin) to 0.81 and 9.59 (cisplatin) to 0.58 , respectively. Additionally, it is of much significance to note that both compounds $\mathbf{5}$ and $\mathbf{6}$ were less cytotoxic toward human normal HUVEC cells than DN603 and DN604. Similar results were shown in the dose-dependent curves of the tested cancer cells to cisplatin, DN604, and compound 5 using MTT assays (Fig. 5A, left). As compound $\mathbf{5}$ surpassed the antitumor activity of cisplatin and chlorambucil, it might act on an extra target different from that of traditional platinum-based compounds. Therefore, compound 5 was chosen for further study.

DNA Platination Induced via Reduction. The cytotoxicity effect of compound $\mathbf{5}$ owing to the DNA platination could be determined in the presence of $\mathrm{EtBr}$ as a probe because the
DNA platination of $\mathrm{Pt}$ could be reduced via the formation of EtBr-DNA complex. The results in Fig. 4A showed that compound $\mathbf{5}$ did not induce much fluorescent intensity change before it was reduced to a $\mathrm{Pt}(\mathrm{II})$ moiety in the presence of ascorbic acid, while cisplatin could definitely lead to the loss of fluorescent intensity. The results indicated that under the activation of reductant ascorbic acid, compound $\mathbf{5}$ can actually exert its cytotoxic effect.

Cellular Uptake. To explore the mechanism of the improved cytotoxicity effect of compound $\mathbf{5}$ compared with cisplatin and DN604, the cellular uptake of cisplatin, DN604, and compound 5 was detected in cisplatin-sensitive and cisplatin-resistant cancer cells. After treatment of 4 hours, the platinum content in these cancer cells was analyzed via ICP technique. Results shown in Fig. 4B, top, indicate the elevated cellular uptakes of compound $\mathbf{5}$ in cisplatin-resistant SGC-7901/CDDP and A549/CDDP cancer cells were dramatically 2.53-fold and 3.31-fold, respectively, higher than that of cisplatin, whereas in cisplatin-sensitive SGC-7901 and A549 
TABLE 1

In vitro cytotoxicity of measured samples

\begin{tabular}{|c|c|c|c|c|c|c|c|}
\hline \multicolumn{8}{|c|}{$\mathrm{IC}_{50}{ }^{a}$} \\
\hline Compounds & SGC-7901 & SGC-7901/CDDP & $\mathrm{A}_{\mu M}$ & A549/CDDP & HUVEC & $\mathrm{RF} 1^{b}$ & $\mathrm{RF}^{c}$ \\
\hline Chlorambucil & $80.25 \pm 10.75$ & $101.64 \pm 18.76$ & $75.85 \pm 10.13$ & $120.98 \pm 19.76$ & $120.98 \pm 19.76$ & & \\
\hline Cisplatin & $1.73 \pm 0.11$ & $12.26 \pm 0.93$ & $2.06 \pm 0.15$ & $19.75 \pm 0.96$ & $10.35 \pm 3.72$ & 7.09 & 9.59 \\
\hline Oxaliplatin & $13.29 \pm 1.91$ & $15.95 \pm 1.83$ & $17.95 \pm 9.08$ & $20.27 \pm 10.82$ & $25.92 \pm 10.05$ & & \\
\hline Carboplatin & $19.28 \pm 7.05$ & $20.13 \pm 7.35$ & $10.98 \pm 3.36$ & $19.27 \pm 9.63$ & $150.21 \pm 24.85$ & & \\
\hline DN603 & $12.84 \pm 3.78$ & $16.59 \pm 7.53$ & $10.32 \pm 8.91$ & $20.39 \pm 10.12$ & $30.72 \pm 13.42$ & & \\
\hline DN604 & $5.13 \pm 0.21$ & $5.09 \pm 0.25$ & $4.59 \pm 0.55$ & $4.01 \pm 0.12$ & $30.85 \pm 15.02$ & 0.99 & 0.87 \\
\hline Compound 5 & $3.59 \pm 0.32^{*}$ & $2.91 \pm 0.12^{* *}$ & $3.38 \pm 0.16$ & $1.95 \pm 0.92^{* *}$ & $50.92 \pm 14.25^{* *}$ & 0.81 & 0.58 \\
\hline Compound 6 & $8.23 \pm 0.75^{* *}$ & $15.28 \pm 7.56$ & $8.05 \pm 0.92 *$ & $20.79 \pm 1.39$ & $49.72 \pm 13.25^{* *}$ & & \\
\hline
\end{tabular}

MTT, 3-(4,5-dimethylthiazol-2-yl)-2,5-diphenyltetrazolium bromide.

${ }^{a} \mathrm{IC}_{50}$ is the drug concentration able to inhibit $50 \%$ of cell viability measured by MTT assay after $72 \mathrm{~h}$ drug exposure.

${ }^{b}$ Resistance factor, $\mathrm{IC}_{50}(\mathrm{SGC}-7901 / \mathrm{CDDP}) / \mathrm{IC}_{50}(\mathrm{SGC}-7901)$.

${ }^{c}$ Resistance factor, $\mathrm{IC}_{50}(\mathrm{~A} 549 / \mathrm{CDDP}) / \mathrm{IC}_{50}$ (A549).

$* P<0.05 ; * * P<0.01$ compared with cisplatin-treated group.

cancer cells, 1.28-fold and 1.23-fold, respectively, lower than that of cisplatin. Notably, the platinum amount of compound $\mathbf{5}$ in HUVEC normal cells was 2.6 -fold lower than that of cisplatin. The results of the $\mathrm{Pt}$ accumulation assays repeated at $4^{\circ} \mathrm{C}$ showed that the incubation of cisplatin-sensitive and -resistant cells at low temperature led to a reduction in the $\mathrm{Pt}$ accumulation, which indicates that compound $\mathbf{5}$ enters the cells through an energy-dependent pathway and not exclusively by passive diffusion (Fig. 4B, bottom).

Moreover, the amount of platinum in the different subcellular compartments of cancer cells was quantified to fetch a more detailed picture of the intracellular localization of platinum complexes (Fig. 4C). As expected for cisplatin, which is known to induce cell death by forming adducts on nucleus DNA, $69 \%$ and $72 \%$ of the total intracellular Pt was located in the nucleus of cisplatin-sensitive SGC-7901 and A549 cancer cells, whereas only $21 \%$ and $29 \%$ in cisplatin-resistant SGC-7901/CDDP and A549/CDDP cancer cells. In contrast, the ratio was $69 \%$ and $72 \%$ for compound 5 in SGC-7901/CDDP and A549/CDDP cancer cells, respectively. These results bode well for a role of compound 5 to effectively bind to genomic DNA and overcome platinum resistance in SGC-7901/CDDP and A549/CDDP cancer cells.

Platinum-based drugs enter the cells by passive diffusion and through carrier-mediated uptake by a number of transport proteins in which several proteins have been identified as possible uptake transporters for platinating compounds (Hall et al., 2008). For copper transporter 1 (Ctr1), which controls intracellular copper homeostasis, an involvement in uptake of cisplatin has been shown (Ishida et al., 2002; Kuo et al., 2007). Thus the levels of $\mathrm{Ctr} 1$ protein in our tests were measured by immunoblotting. The results indicated that the amount of Ctr1 was reduced in cisplatin-resistant cancer cells compared with cisplatin-sensitive cancer cells, suggesting that reduced expression of Ctr1 contributed to the observed low levels of cisplatin in SGC-7901/CDDP and A549/CDDP cancer cells (Fig. 4D). It is discussed that chelator-mediated copper starvation leads to a conformational change of Ctr1, allowing more cisplatin to be transported into the cells resulting in the observed increased platinum levels. When SGC-7901 and A549 cancer cells were pretreated with TM for 24 hours and then incubated with cisplatin for 2 hours, we observed an up to 1.3-fold and 1.2-fold increase in intracellular platinum accumulation compared with cells incubated with cisplatin alone
(Fig. 4E, top). In contrast, intracellular platinum accumulation after incubation with compound $\mathbf{5}$ was not affected by TM in cisplatin-sensitive SGC-7901 and A549 cancer cells. As Ctr1 is expressed at low levels in cisplatin-resistant SGC-7901/CDDP and A549/CDDP cancer cells, manipulation of only few transporters might not exert a major influence on cisplatin uptake. Altogether these data support the hypothesis that compound $\mathbf{5}$ is mainly taken up by passive diffusion, whereas active transport mechanisms by Ctr1 seem to play a minor role. As a consequence, a change in active uptake mediated by transport proteins, observed in cisplatin-resistant SGC-7901/CDDP and A549/CDDP cancer cells, would not affect the influx of compound $\mathbf{5}$ (Fig. $4 \mathrm{E}$, bottom). This has been confirmed in our model system of cisplatin-sensitive versus cisplatin-resistant cell lines where the platinum accumulation of compound $\mathbf{5}$ was similar in both cell lines, suggesting that reduced active uptake mechanisms do not affect influx of compound $\mathbf{5}$.

Cellular Responses. To further explore the cytotoxicity effect of compound $\mathbf{5}$, we evaluated its inhibition efficiency to cisplatin-sensitive A549 and cisplatin-resistant A549/CDDP cancer cell lines via cell growth inhibition, apoptosis, and colony forming assays (Fig. 5). Cells were incubated with $15 \mu \mathrm{M}$ of chlorambucil, cisplatin, DN604, and compound 5, respectively, in culture medium. The results in Fig. 5A, right, indicated that compound 5 exhibited better cytotoxic ability on cisplatin-resistant A549/CDDP cancer cells than cisplatin. To evaluate whether their cytotoxicity effects were associated with cell apoptosis, an Annexin V/PI staining was employed. Cancer cells were incubated with $15 \mu \mathrm{M}$ of chlorambucil, cisplatin, DN604, and compound 5, respectively, for 24 hours. The results, shown in Fig. 5B, indicated that compound 5 could induce apoptosis much more effectively than cisplatin and DN604 in A549/CDDP cancer cells, whereas chlorambucil alone did not induce apoptotic changes, suggesting that a significant cytotoxicity effect of compound $\mathbf{5}$ was due to promoting cancer cell apoptosis.

The caspase-3 activity in cancer cells was determined at concentration of $15 \mu \mathrm{M}$ of chlorambucil, cisplatin, DN604, and compound 5, respectively, for 24 hours. The cells incubated with compound $\mathbf{5}$ showed a high degree of caspase-3 activity compared with cisplatin and DN604 in A549/CDDP cancer cells (Fig. 5C). These findings indicated that compound $\mathbf{5}$ might induce higher level of 
A
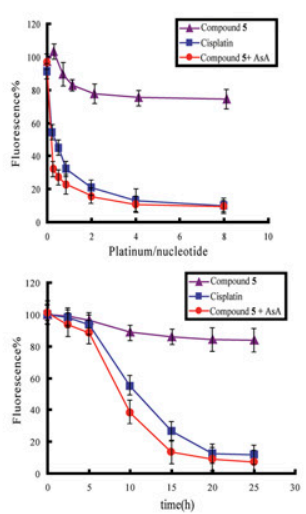

C

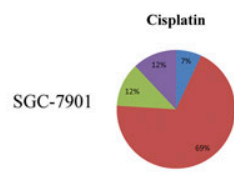

Cisplatin
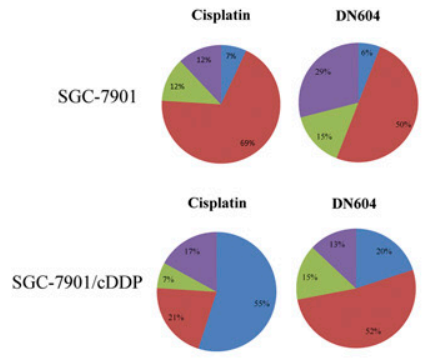

B
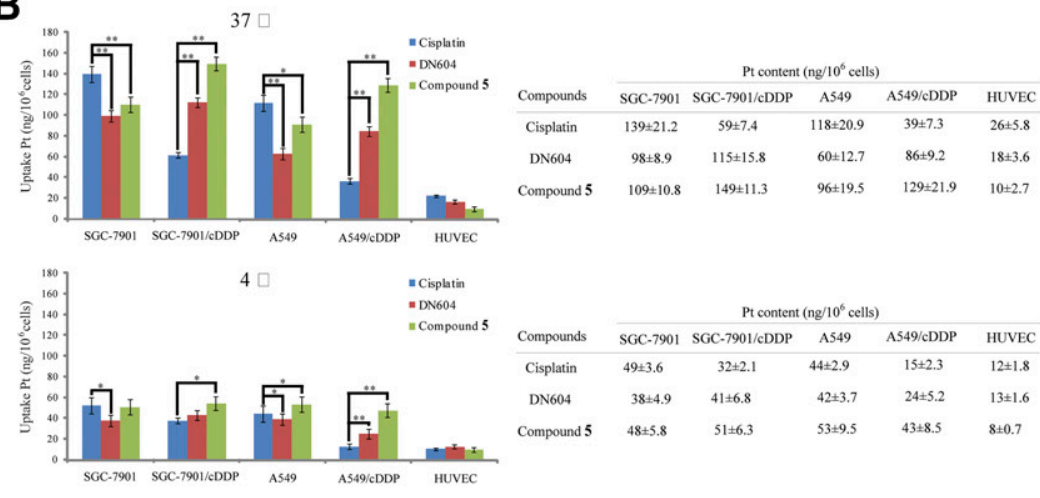

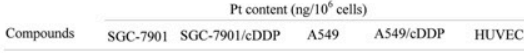

\begin{tabular}{llllll}
\hline Cisplatin & $49 \pm 3.6$ & $32 \pm 2.1$ & $44 \pm 2.9$ & $15 \pm 2.3$ & $12 \pm 1.8$
\end{tabular}

$\begin{array}{llllll}\text { DN604 } & 38 \pm 4.9 & 41 \pm 6.8 & 42 \pm 3.7 & 24 \pm 5.2 & 13 \pm 1.6\end{array}$

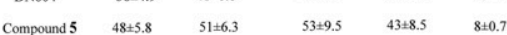

\section{D}
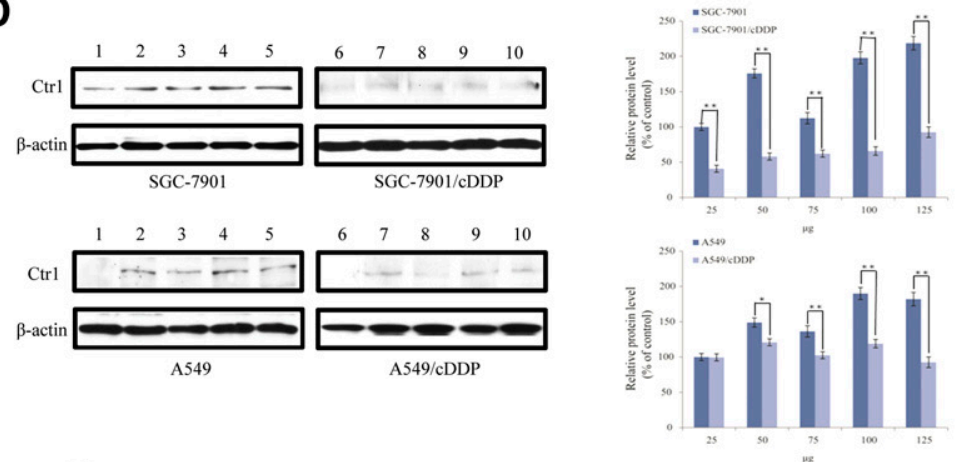

$\mathbf{E}$
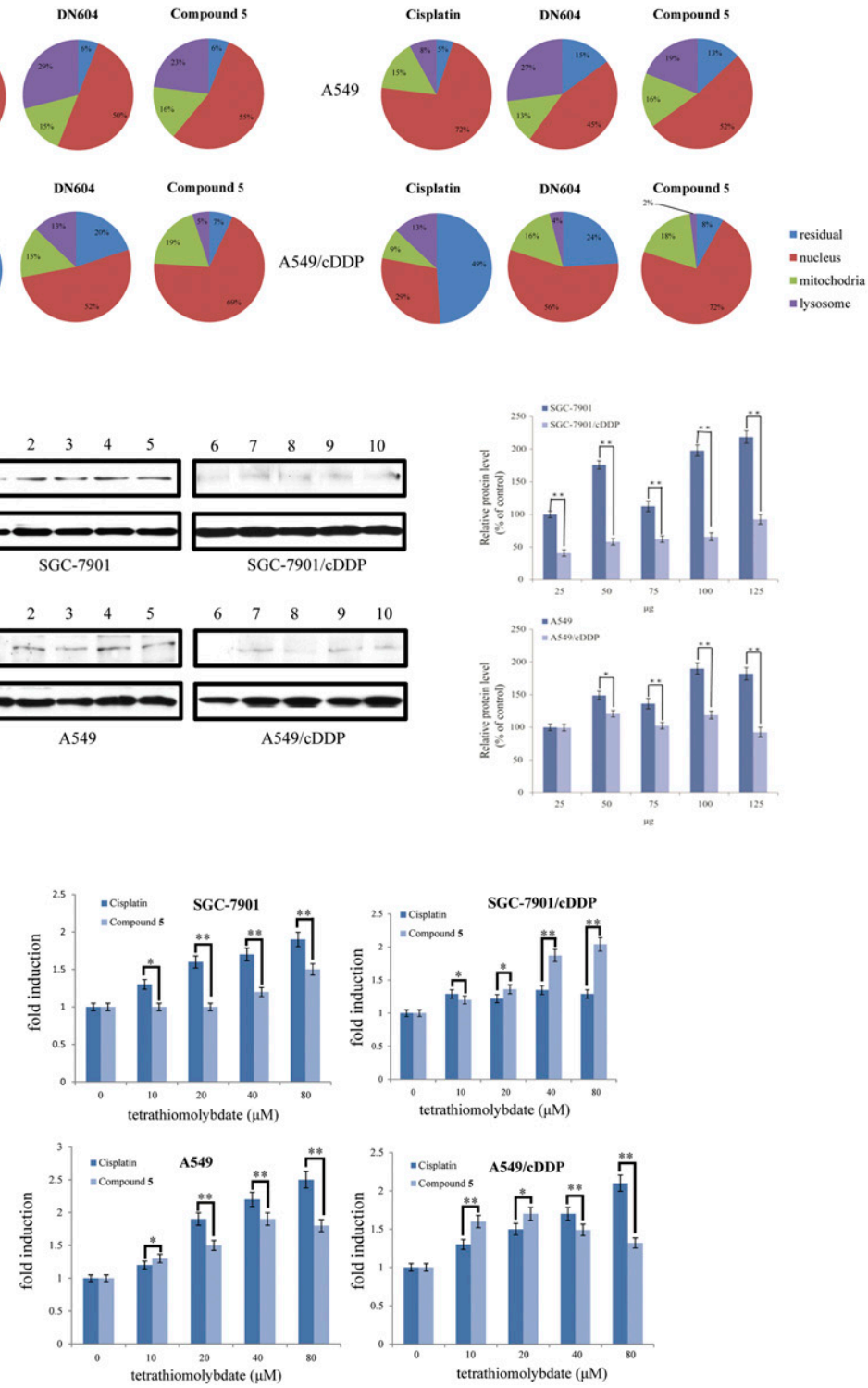

Fig. 4. Reactions of compound 5 with DNA by reduction and the cellular uptake of Pt in cisplatin-sensitive and cisplatin-resistant cancer cells. (A) The different Pt/nucleotide ratios and time of DNA platination. All the reactions were conducted with $0.01 \mathrm{mg} / \mathrm{ml} \mathrm{DNA} \mathrm{in} 10 \mathrm{mM} \mathrm{NaClO} \mathrm{m}_{4}$ in $10 \mathrm{mM}$ phosphate buffer $(\mathrm{pH}=7.4)$ at $37^{\circ} \mathrm{C}$ for 24 hours and then $0.04 \mathrm{mg} / \mathrm{ml} \mathrm{EtBr}$ was added before the fluorescence measurements with the excitation wavelength of $546 \mathrm{~nm}$ and the emission wavelength of $590 \mathrm{~nm}$. (B) The cellular uptake of measured compounds in cancer and normal cells at $37^{\circ} \mathrm{C}$ and $4^{\circ} \mathrm{C}$. (C) The accumulation of the measured compounds in mitochondria, lysosomes, and nucleus of different cancer cells. (D) Western blot analysis of Ctr1 protein in different cancer cells; $25 \mu \mathrm{g}$ protein extract (lanes 1,6), $50 \mu \mathrm{g}$ protein extract (lanes 2, 7), $75 \mu \mathrm{g}$ (lanes 3, 8), $100 \mu \mathrm{g}$ protein extract (lanes 4, 9), and 125 $\mu \mathrm{g}$ protein extract (lanes 5 , 10) are separated on a $12 \%$ polyacrylamide gel. Densitometric analysis was performed to determine the relative ratios of each protein. (E) Platinum 
caspase-dependent apoptosis than cisplatin in cisplatinresistant cancer cells.

The CFA assay (CFA) is an extensively used and wellestablished method for testing chemotherapeutic agents in vitro (Li et al., 2009), reflecting the ability of chemotherapeutic agents to prevent the cell from dividing. To further detect the effect of cell proliferation inhibition of compound $\mathbf{5}$, we used the colony forming assay to compare the ability of compound $\mathbf{5}$ and cisplatin to prevent the proliferation of cisplatin-sensitive A549 and cisplatin-resistant A549/CDDP cancer cell lines. Cells were treated with $15 \mu \mathrm{M}$ of chlorambucil, cisplatin, DN604, and compound $\mathbf{5}$, respectively, for 7 days. As shown in Fig. 5D, fewer colonies apparently survived on the plates exposed to compound $\mathbf{5}$ than those on the plates treated with cisplatin. Thus compound $\mathbf{5}$ was more effective than cisplatin in overcoming the drug resistance of A549/CDDP cancer cells.

Compound 5 Induced Cell Cycle Arrest, Disturbed $\mathrm{Ca}^{2+}$ and $\mathrm{K}^{2+}$ Homeostasis, and Decreased $\Delta \Psi_{\mathrm{m}}$. Since antitumor platinum drugs can usually block the DNA synthesis to induce cell apoptosis, the effect on cell cycle progression of compound 5 was examined. Cisplatin-sensitive A549 and A549/CDDP cancer cells were treated with $15 \mu \mathrm{M}$ of chlorambucil, cisplatin, DN604, and compound 5, respectively, for 24 hours, then cell cycle distribution was determined. It has been reported that cisplatin can arrest the cells at the $\mathrm{S}$ phase. In our experiment, compared with the untreated cells, the number of A549 and A549/CDDP cancer cells in the S phase increased from $32.75 \%-47.53 \%$ to $32.95 \%-38.62 \%$ when treated with cisplatin (Fig. 6A). Chlorambucil also arrested the cells at the S phase (35.17\% and $36.28 \%$ ), slightly weaker than cisplatin. As for compound $\mathbf{5}$, the number of cells arrested at the S phase increased to $61.75 \%$ in A549/CDDP cancer cells, the best among the groups. The results proved that compound 5 still acted on DNA and contributed to the cycle arresting of the cisplatin-resistant cancer cells. Additionally, it was obvious that chlorambucil can strengthen the ability of the Pt(IV) complex to arrest the cell cycle.

As $\mathrm{K}^{+}$efflux has frequently been observed in apoptosis, we measured the extracellular $\mathrm{K}^{+}$concentrations in treated and untreated cancer cells (Kondratskyi et al., 2015). As displayed in Fig. 6B, compound 5 elicited a gradual release of $\mathrm{K}^{+}$to the extracellular environment, with peak extracellular concentrations (increased by $69.27 \%$ and $55.69 \%$ in A549 and A549/CDDP, respectively) observed at 4 hours after treatment. On the other hand, extracellular $\mathrm{K}^{+}$concentrations increased by $89.75 \%$ and $27.37 \%$ in the cisplatin-treated A549 and A549/CDDP cells after 4 hours. These results indicated that compound $\mathbf{5}$ gradually increased $\mathrm{K}^{+}$leakage compared with cisplatin, supporting the idea that compound $\mathbf{5}$ might cause apoptosis higher than cisplatin in A549/CDDP cancer cells.

$\mathrm{Ca}^{2+}$ particularly plays an important role in apoptosis (Pinton et al., 2008), whose uptake by mitochondria is related to the activation of apoptotic factors, like caspase and cytochrome c (Foti et al., 2012). Thus we investigated levels of cytosolic and mitochondrial $\mathrm{Ca}^{2+}$. Fura-2 AM reacts with cytosolic $\mathrm{Ca}^{2+}$ and Rhod-2 AM, which easily enters mitochondria because of its cations and reacts with mitochondrial $\mathrm{Ca}^{2+}$. The results in Fig. 6C showed that compound 5 induced an increase in cytosolic and mitochondrial $\mathrm{Ca}^{2+}$ compared with cisplatin-treated cells. As compound 5 causes mitochondrial $\mathrm{Ca}^{2+}$ accumulation, the loss of $\Delta \Psi_{\mathrm{m}}$ following breakdown of ion homeostasis can be induced. Considering that loss in $\Delta \Psi_{\mathrm{m}}$ is an important proapoptotic index for early apoptosis, we chose a mitochondria-specific and voltage-dependent fluorescent probe, JC-1, to observe whether there was loss in $\Delta \Psi_{\mathrm{m}}$. The results from flow cytometry showed that compound $\mathbf{5}$ could make $\Delta \Psi_{\mathrm{m}}$ decrease mostly compared with cisplatin (Fig. 6D). Since ATP production is a significant consequence attributed to the dysfunction of mitochondrial energy production, we measured intracellular ATP levels after compound 5 treatment. As shown in Fig. 6E, the ATP level in cells treated with compound $\mathbf{5}$ at $15 \mu \mathrm{M}$ decreased to $12.83 \%$ and $7.96 \%$ of untreated A549 and A549/CDDP cancer cells, respectively, which was $5.74 \%$ and $23.91 \%$ lower than that of cisplatin-treated cells.

Compound 5 Induced ROS and $\mathrm{H}_{2} \mathrm{O}_{2}$ Generation of Cancer Cells. Reactive oxygen species (ROS) play important roles in a variety of physiological and pathophysiological processes (Finkel and Holbrook, 2000). Previous explorations reported that excess accumulation of ROS is associated with disruption of mitochondrial membrane potential (MMP), therefore triggering a series of mitochondria-associated events including apoptosis (Park et al., 2005). Moreover, there has been a report that metal complexes may cause the accumulation of reactive oxygen species (ROS) and DNA damage, resulting in cell arrest and apoptosis eventually (Deng et al., 2015). Thus the generation of ROS was investigated to further analyze the anticancer mechanism of compound 5. Cells were treated with $15 \mu \mathrm{M}$ of chlorambucil, cisplatin, DN604, or compound 5, respectively, for 6 hours, stained with $10 \mathrm{mM} \mathrm{H}_{2}$ DCFDA for 30 minutes and then analyzed by flow cytometry. After incubation, cisplatin did not show apparent effect on the level of ROS compared with the control group in A549/CDDP, whereas the level of ROS cells increased after the treatment with chlorambucil as expected. As for compound 5, the ROS level increased (Fig. 6F), which was definitely higher than other groups in cisplatin-resistant A549/CDDP cells.

Taking into account that among all ROS and other oxygenderived free radicals, $\mathrm{H}_{2} \mathrm{O}_{2}$ was recently suggested to act as a central player in signal transduction pathways (Halliwell and Cross, 1994), we evaluated $\mathrm{H}_{2} \mathrm{O}_{2}$ generation by a fluorometric assay in cancer cells incubated in the presence of $15 \mu \mathrm{M}$ of chlorambucil, cisplatin, DN604, and compound 5, respectively. $\mathrm{H}_{2} \mathrm{O}_{2}$ measurement was carried out after 2-hour incubations with chlorambucil and cisplatin, DN604, and compound 5, respectively. The production of $\mathrm{H}_{2} \mathrm{O}_{2}$ was significantly higher in cancer cells incubated with compound 5 than those in cells treated with chlorambucil along and cisplatin in cisplatin-resistant A549/CDDP cancer cells

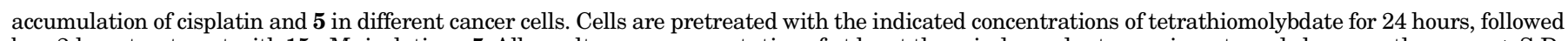

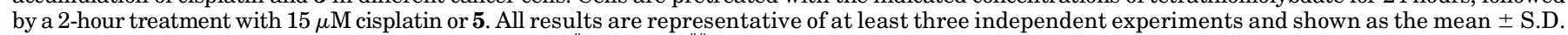
${ }^{*} P<0.05$; ${ }^{*} P<0.01$ compared with control group. ${ }^{\#} P<0.05$; ${ }^{\# \#} P<0.01$ compared with chlorambucil-treated or control group. 
A
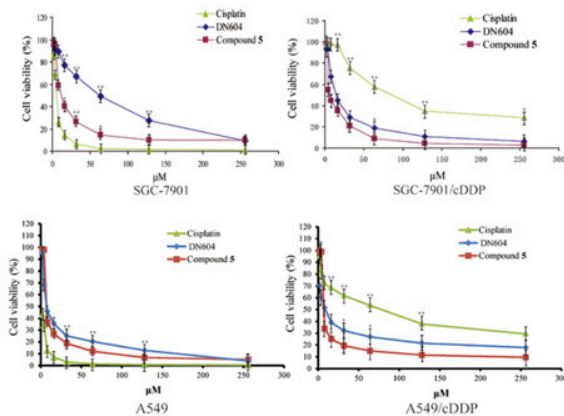

C
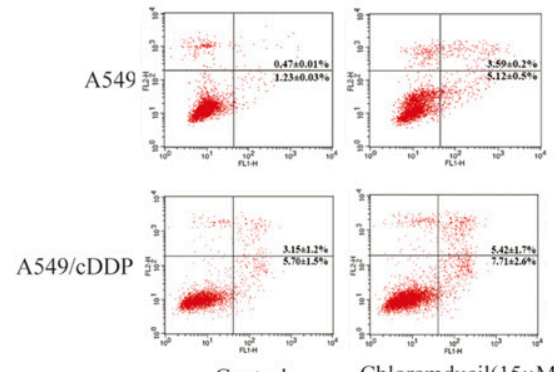

Control

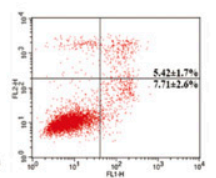

Chloramducil $(15 \mu \mathrm{M})$

D

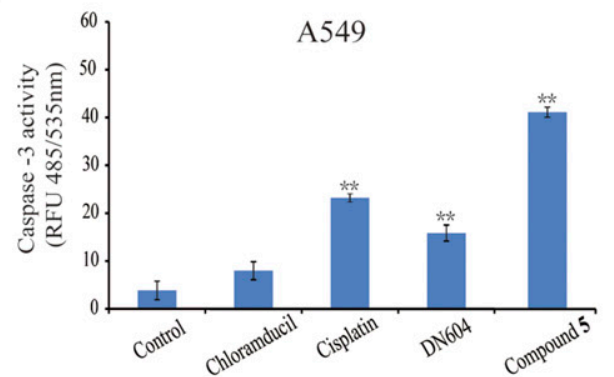

E

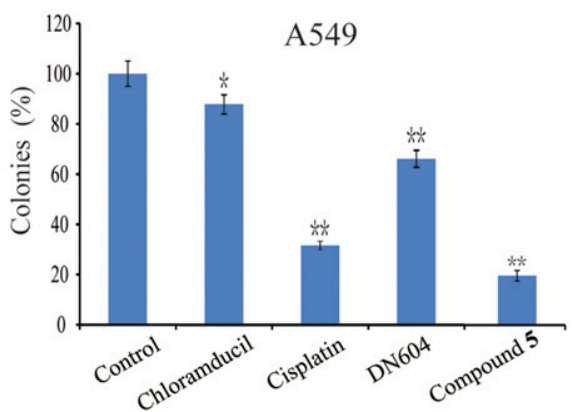

B

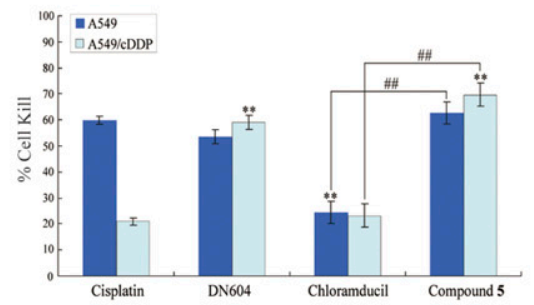

$$
\text { - A549 }
$$

- A549/cDDP
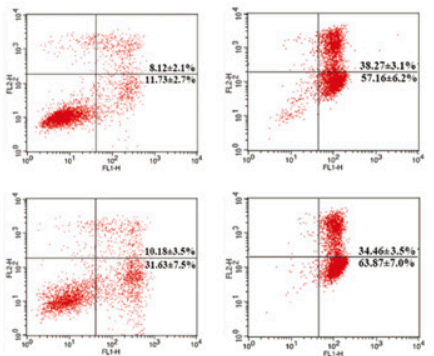

DN604 $(15 \mu \mathrm{M})$

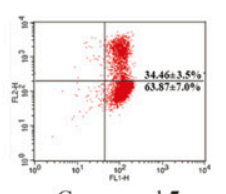

Compound 5

$(15 \mu \mathrm{M})$
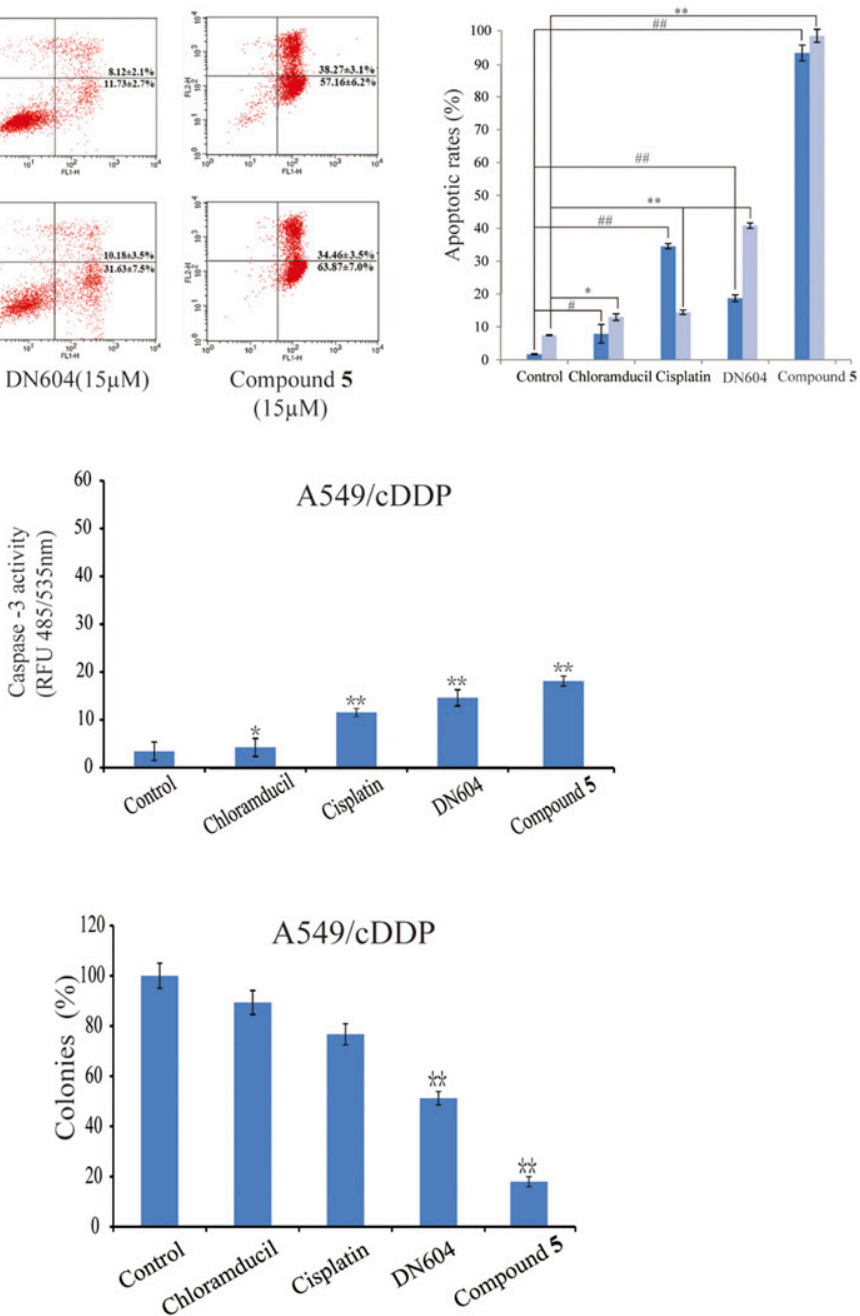

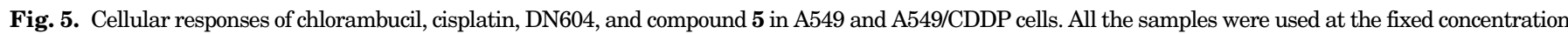

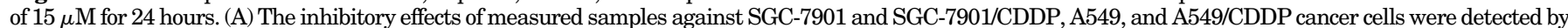

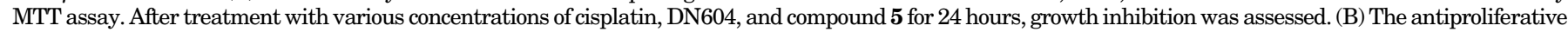

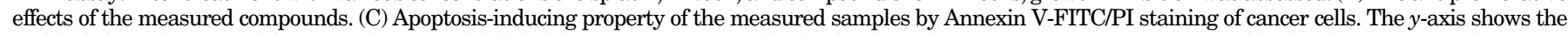

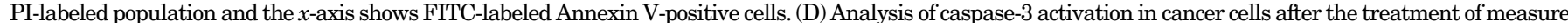

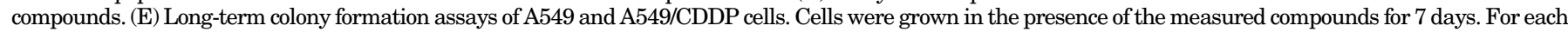

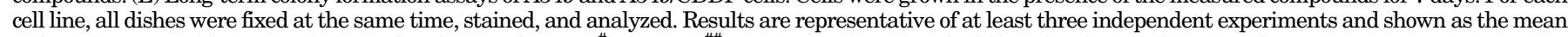
\pm S.D. ${ }^{*} P<0.05$; ${ }^{* *} P<0.01$ compared with control group. ${ }^{\#} P<0.05 ;{ }^{\# \#} P<0.01$ compared with chlorambucil-treated or control group.

(Fig. 6G). The results strongly suggested that compound $\mathbf{5}$ could induce increased intracellular oxidative stress compared with chlorambucil and cisplatin, thus triggering cisplatin-resistant cancer cell apoptotic pathways.
Biomarkers of DNA Damage. Following the treatment of compound 5, we measured intracellular GSH levels in cisplatin-sensitive and cisplatin-resistant cancer cells. As illustrated in Fig. 7A, the cisplatin-resistant A549/CDDP 
A
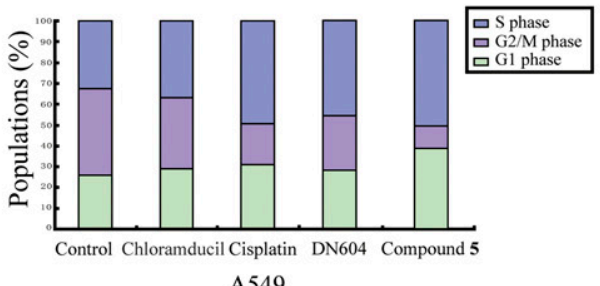

B

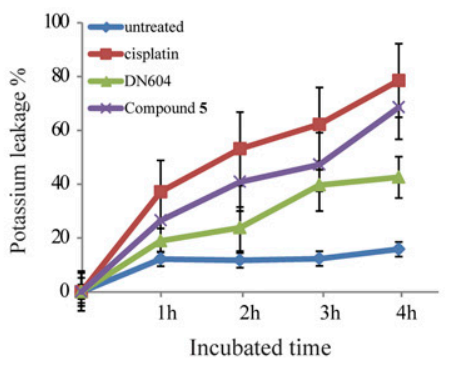

A549

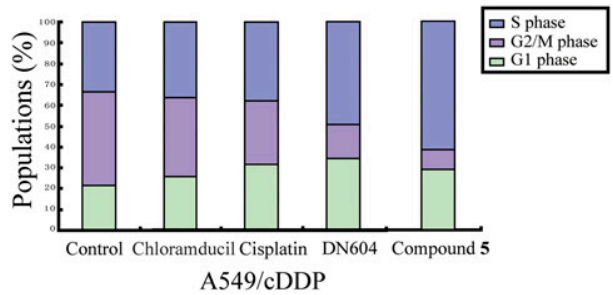

C
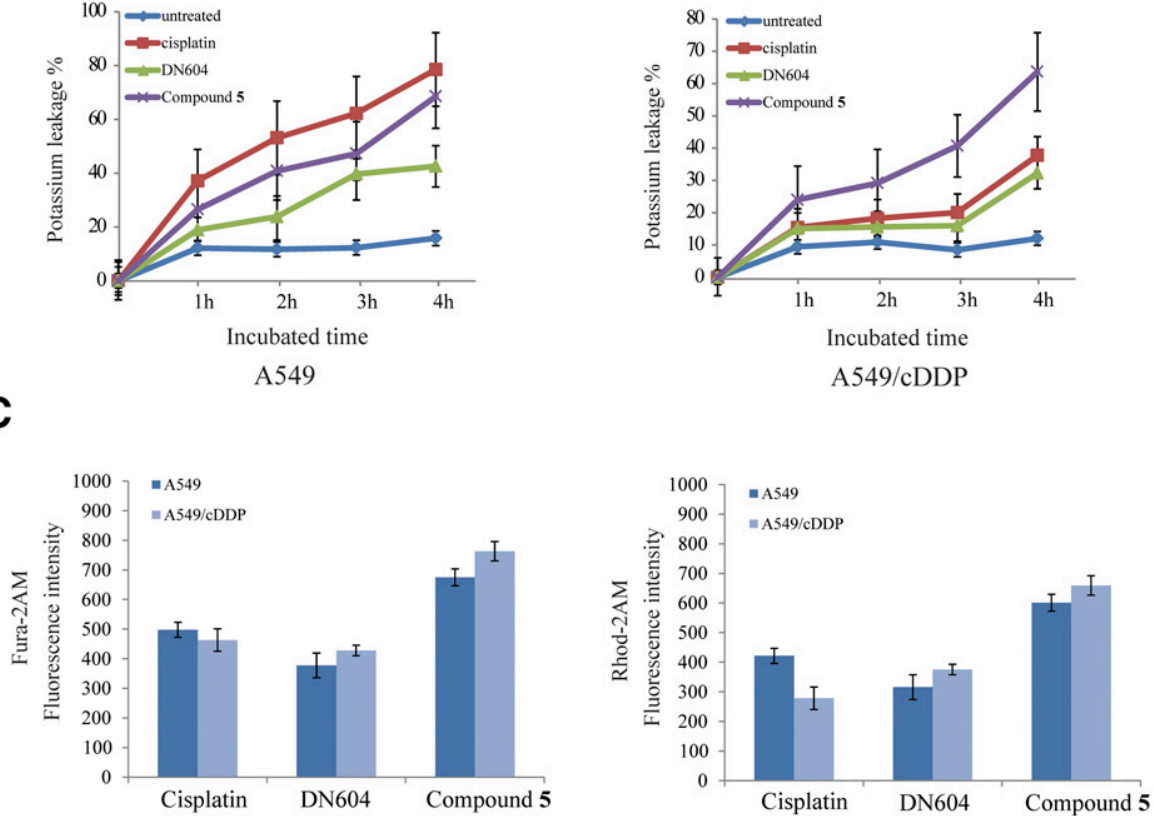

A549/cDDP

D

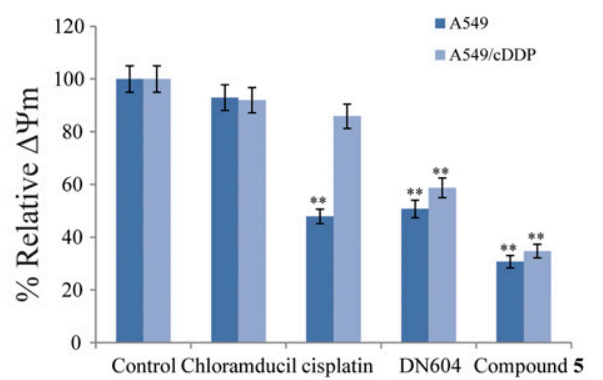

F

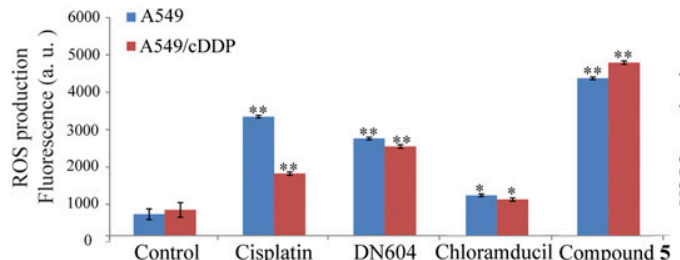

E

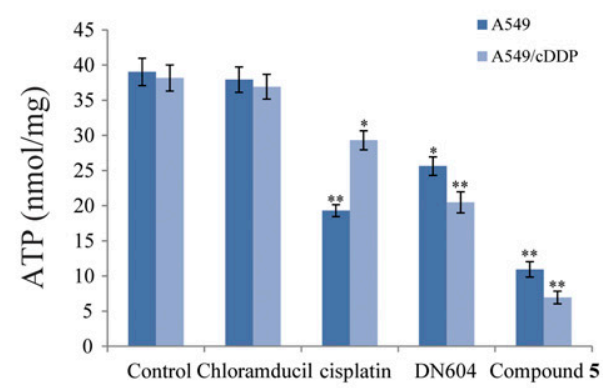

G

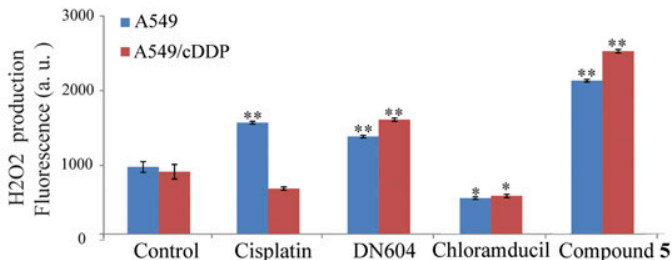

Fig. 6. Compound 5 induces cell death and cell cycle changes in A549 and A549/CDDP cancer cells. (A) Cell cycle analysis upon exposure to compound 5 . A549 and A549/CDDP cancer cells exposed to the measured compounds for 72 hours were stained with propidium iodide and subjected to flow cytometry analysis. Analysis of $\mathrm{K}^{+}$and $\mathrm{Ca}^{2+}$ levels after treatment with measured samples. (B) The relative amounts of extracellular $\mathrm{K}^{+}$were measured every 1 hour. (C) Spectrofluorophotometric analysis of cytosolic and mitochondrial $\mathrm{Ca}^{2+}$ levels using Fura-2 AM and Rhod-2 AM, respectively. The mitochondrial membrane potential (D) and the intracellular ATP (E) decreased in compounds-treated A549 and A549/CDDP cancer cells. (D) Cells were exposed to chlorambucil, cisplatin, DN604, and compound $5(15 \mu \mathrm{M})$ for 24 hours, stained with JC-1, and visualized under an inverted fluorescence 
A

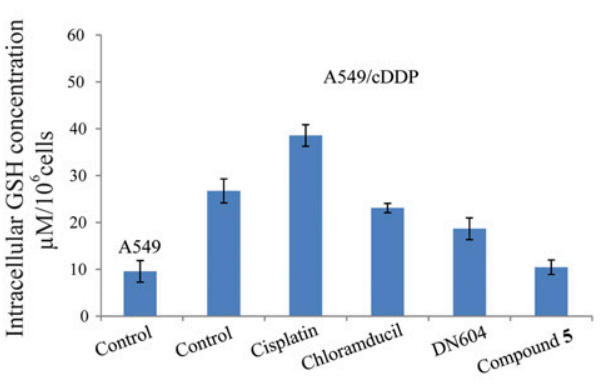

B

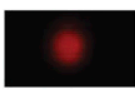

A549/cDDP

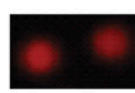

Control
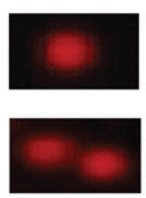

Chloramducil
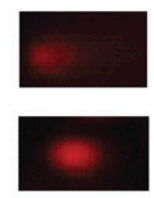

Cisplatin
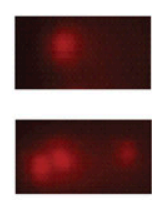

DN604
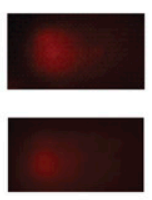

Compound 5

\begin{tabular}{|c|c|c|c|c|c|}
\hline & Control & Chloramducil & Cisplatin & DN604 & Compound 5 \\
\hline Tail Length & $6.59 \pm 1.35 / 7.02 \pm 1.01$ & $12.94 \pm 2.24 / 22.47 \pm 3.21$ & $39.73 \pm 13.15 / 26.87 \pm 11.92$ & $27.96 \pm 12.19 / 17.82 \pm 9.75$ & $57.93 \pm 19.72 / 39.84 \pm 15.62$ \\
\hline Tail Moment & it $1 / 27 \pm 1.12 / 1.32 \pm 0.64$ & $0.95 \pm 0.06 / 2.15 \pm 0.91$ & $8.43 \pm 0.68 / 5.16 \pm 0.41$ & $8.82 \pm 0.12 / 3.47 \pm 0.95$ & $19.28 \pm 9.21 / 6.04=$ \\
\hline & $7 \pm 0$ & 0.95 & $3.19 \pm 1$. & $2.41 \pm 0.81 / 1.37 \pm 0.91$ & $7.38 \pm 2.04 / 6.71 \pm 0.94$ \\
\hline
\end{tabular}

C
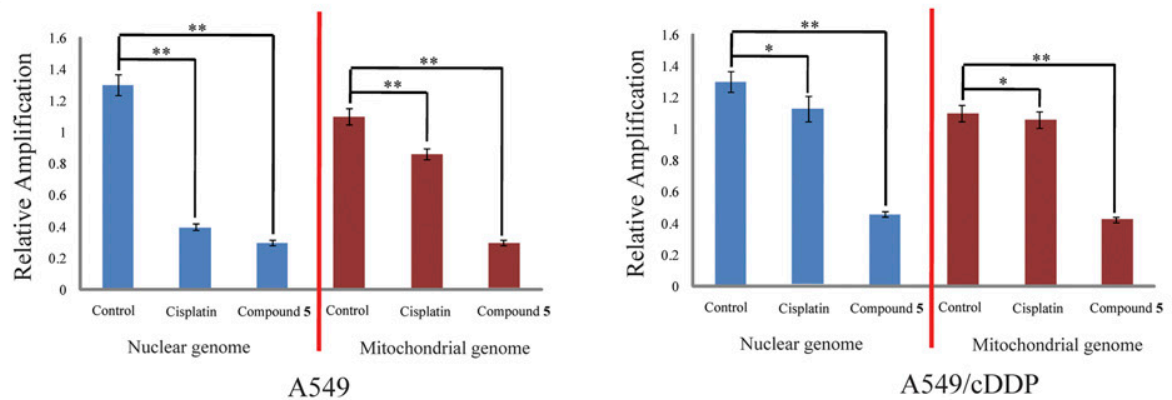

A549/cDDP

D

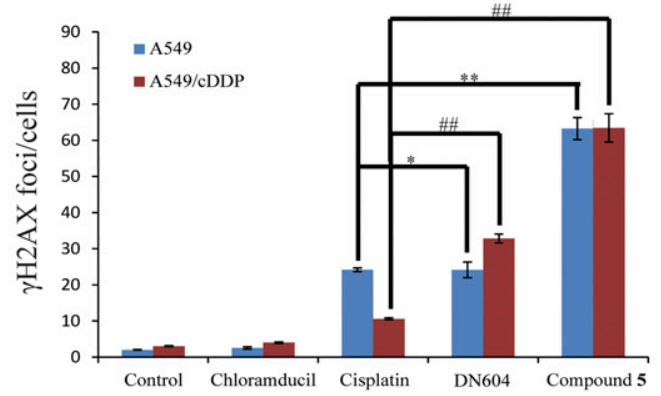

Fig. 7. Intracellular GSH concentrations and DNA damage of the measured compounds. (A) A549 and A549/CDDP cells were incubated with chlorambucil, cisplatin, DN604, and $5(15 \mu \mathrm{M})$ for 4 hours. (B) Comet assay revealing increased chromosomal DNA strand breaks triggered by the measured compounds in A549 and A549/CDDP cells. (C) Compound 5 induced DNA damage in the nuclear genome and mitochondrial genome. (D) Intracellular DNA damage of the measured compounds. $\gamma \mathrm{H} 2 \mathrm{AX}$ foci after treatments was counted in $50-60$ individual cells per time points of 12 hour in A549 and A549/CDDP cells. Results are representative of at least three independent experiments and shown as the mean \pm S.D. ${ }^{*} P<0.05 ; * * P<0.01$ compared with control group. ${ }^{\#} P<0.05$ compared with cisplatin-treated group.

cancer cells expressed higher levels of intracellular GSH than the cisplatin-sensitive A549 cancer cells. When A549/CDDP cancer cells were treated in $800 \mathrm{ng} / \mathrm{ml}$ cisplatin for 4 hours, intracellular GSH levels increased. However, GSH levels did significantly reduce when treated with compound 5. These results proved that compound 5 reduces intracellular GSH levels to improve active platinum delivery to the DNA to interact with cellular components and causes severe DNA damage (You et al., 2009; Foti et al., 2012). As shown in Fig. 7B, compound 5 produced dramatically prominent tails

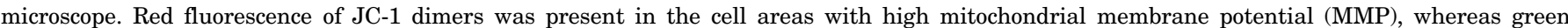

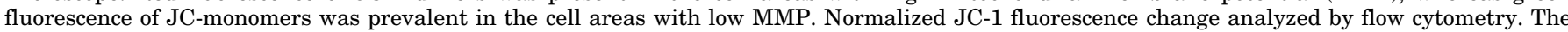

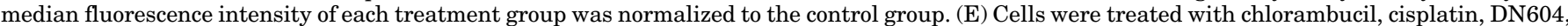

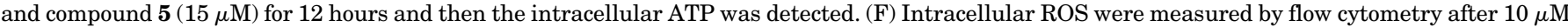

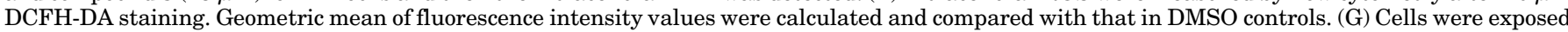

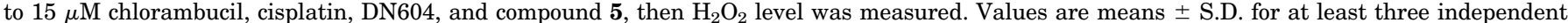
experiments performed in triplicate $(* P<0.05 ; * * P<0.01$ compared with vehicle control). 
induced by SSBs, DSBs, and active DNA crosslink excision breaks in contrast to cisplatin in three major parameters (tail length, tail moment, olive tail moment). The data obviously showed that compound $\mathbf{5}$ could effectively cause DNA damage in A549 and A549/CDDP cells compared with DN604 and cisplatin alone, thereby leading to cancer cell apoptosis.

Because the chlorambucil-conjugated Pt(IV) hybrid could accumulate in both the mitochondria and nucleus in cancer cells, the effects of DNA damage delivered by cisplatin and compound $\mathbf{5}$ on the two genomes were determined by PCR amplification of DNA. A $17.7-\mathrm{kb}$ segment of $\mathrm{nDNA}$ at the $\beta$-globin gene and an 8.9-kb fragment of mtDNA were used for detection following cancer cells treated with cisplatin and compound 5. As shown in Fig. 7C, cisplatin primarily damaged nDNA with a few mitochondrial lesions, whereas compound 5 caused a significant reduction of mitochondrial genome amplification with similar effect on the nuclear genome. Thus compound $\mathbf{5}$ mainly damaged nDNA and mtDNA, although most intracellular Pt accumulated in the nucleus.

To detect the DSBs induced by the measured samples, we determined the phosphorylated histone H2AX $(\gamma \mathrm{H} 2 \mathrm{AX})$, the known earliest detectable marker of DSB. Two cancer cells were treated with the measured samples at the fixed concentration of $15 \mu \mathrm{M}$ for 12 hour, respectively. As shown in the flow cytometry assessment of $\gamma \mathrm{H} 2 \mathrm{AX}$ in A549 and A549/CDDP treated with corresponding samples (Fig. 7D), compound 5 produced increased level of discrete $\gamma \mathrm{H} 2 \mathrm{AX}$ foci compared with cisplatin for 12 hours, proving that the extent of DSBs increased apparently in two cancer cells, especially in the cisplatin-resistant cancer cells. However, such changes were not apparently observed after the treatment of cisplatin. Under these conditions, the DNA damage of DSBs and SSBs revealed the possibility that the increased level of DSBs induced by compound $\mathbf{5}$ is much higher than that of SSBs in cancer cells compared with cisplatin. The result implied that the most lethal attack of DSBs plays an important role in compound 5-triggered serious cell apoptosis, which probably accounts for the improved cellular uptake of Pt.

Compound 5 Repressed MRE11-RAD50-NBS1 Complex Protein Expression in DSB Repair Response. To reveal the mechanisms underlying the enhanced cytotoxicity and the resistance prevention, compound $\mathbf{5}$ was studied to learn whether it could reduce the activation of DNA repair response including activation of DSB repair protein MRE11RAD50-NBS1(MRN) complex within the nucleus. Treatment of A549/CDDP cells with $15 \mu \mathrm{M}$ compound 5 for 24 hours led to a dramatic decrease in the expression of MRN complex protein to the damaged DNA compared with cisplatin (Fig. 8A). The results revealed that compound $\mathbf{5}$ could inhibit MRN complexinduced DSB repair caused by its ability of increasing cellular uptake of $\mathrm{Pt}$ compared with those of cisplatin.

Compound 5-Induced Suppression of DSB Repair could be Mimicked in MRN-deficient Cells. Activation of DSB repair protein MRE11-RAD50-NBS1(MRN) complex suggested an important role of MRN complex to DSBs. The key subunit of the MRN complex, MRE11, interacts with PIH1D1 and contains additional protein-protein interaction domains important for MRN function in the DDR. The MRE11 C-terminal part contains two potential DNA-binding domains and a glycine-arginine-rich motif, involved in the regulation of MRE11 nuclease activity and DNA binding (Dery et al., 2008; Yu et al., 2012).
To study the role of MRE11 played in compound 5-induced suppression of DSB repair, we transfected wild-type and siMRE11 to A549/CDDP cancer cells and monitored the repair kinetics of DSB via imaging the discrete $\gamma \mathrm{H} 2 \mathrm{AX}$ foci in A549/CDDP cancer cells. The similar repair kinetics of DSB observed in A549/CDDP cancer cells (Fig. 8B) indicated that MRE11 is necessary for the inhibition of DSB repair induced by compound 5. Meanwhile, the suppression of DSB repair induced by compound 5 could be enhanced in MRE11 ${ }^{-/-}$cells (Fig. 8C), demonstrating that the deficient MRE11 could mimic the inhibitory ability of compound $\mathbf{5}$ in DSB repair. These data implied a critical role of MRE11 in compound 5-induced DSB suppression and resistance prevention.

The Key Role of CK2 in Compound 5-Mediated MRE11 Activation and Reversed Cisplatin Resistance in A549/CDDP Cancer Cells. MRE11 could directly interact with PIH1D1, which is required for the assembly of MRN complex. The MRE11-PIH1D1 interaction is dependent on casein kinase 2 (CK2) phosphorylation of two acidic sequences within the MRE11 C terminus containing serines $558 / 561$ and 688/689. Consistent with the findings, depletion of $\mathrm{CK} 2$ resulted in MRE11 destabilization and decreased assembly of the MRN complex, hindering the DNA damage repair processes (von Morgen et al., 2017). We investigated whether compound 5 directly inhibits CK2 activity. The results from the CK2 kinase assay indicated that compound 5 significantly suppressed CK2 activity (Fig. 8D). As shown in Fig. 8E, transfection of either CK2 $\alpha$ or $\mathrm{CK} 2 \beta$ subunits or both gives rise to the expected patterns with the anti-Myc antibody. A $75 \%, 18 \%$, and $109 \%$ increase in CK2 activities from A549/CDDP cells that were transfected with CK2 $\alpha$ or CK2 $\beta$ or both was observed compared with the control. Results of the MRE11 protein expression assay in Fig. $8 \mathrm{~F}$ exhibited $28 \%$ and $75 \%$ increases in cells transfected of CK2 $\alpha$ or both. These data provide evidence that both $\mathrm{CK} 2 \alpha$ and $\mathrm{CK} 2 \beta$ are required for MRE11 activation. The results in Fig. 8G indicated that the increased MRE11 protein expression could be inhibited in compound 5-treated A549/CDDP cancer cells cotransfected with $\mathrm{CK} 2 \alpha$ and $\mathrm{CK} 2 \beta$. The results from the CFA assay, shown in Fig. $8 \mathrm{H}$, indicated that the increased colonies survived on the plates exposed to compound $\mathbf{5}$ in the cells co-transfected with CK2 $\alpha$ and CK2 $\beta$, compared with empty vector. Moreover, the cell death of A549/CDDP treated with compound 5 was reduced in the presence of CK $2 \alpha$ and CK2 $\beta$ subunits (Fig. 8I). These results demonstrated that $\mathrm{CK} 2 \alpha / \beta$ was involved in compound $\mathbf{5}$ suppression of MRE11 activation in A549/CDDP cancer cells.

In Vivo Antitumor Activity. In vivo antitumor efficacy of compound 5 on the A549/CDDP tumor xenograft mice model was assayed together with cisplatin, DN604, and chlorambucil. Compound 5 (dosed intravenously at $5 \mathrm{mg} / \mathrm{kg}$ once a week), cisplatin (dosed intravenously at $5 \mathrm{mg} / \mathrm{kg}$ once a week), and DN604 (dosed intravenously at $5 \mathrm{mg} / \mathrm{kg}$ once a week), chlorambucil (dosed intravenously at $5 \mathrm{mg} / \mathrm{kg}$ once a week) were conducted into four nude mice groups. The tumor volumes, measured using vernier calipers every 2 days in a period of 21 days, indicated that compound 5 can effectively inhibit the tumor growth (Fig. 9A). At the end of the 21-day period, the tumor weight was measured to detect the antitumor activity of these measured groups. The tumor growth inhibition rate of compound 5 reached $75.81 \%$, whereas that of cisplatin at the same dose as compound $\mathbf{5}$ was only $22.58 \%$. 
A
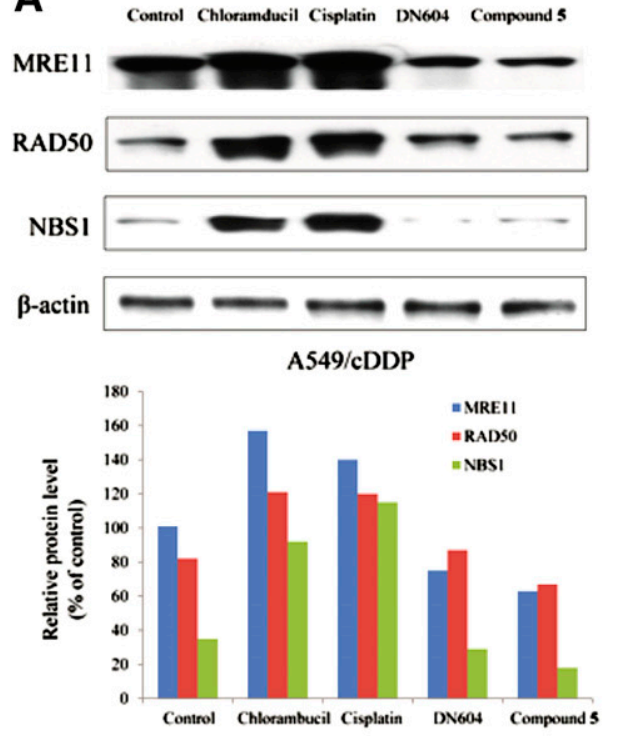

D

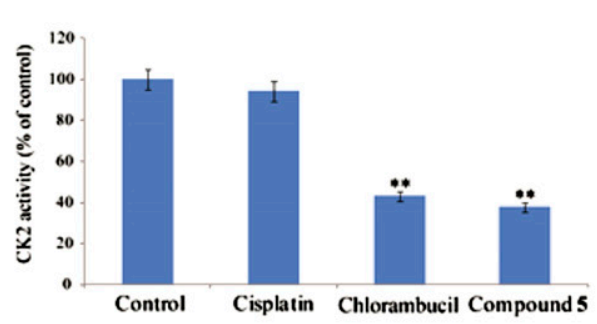

B

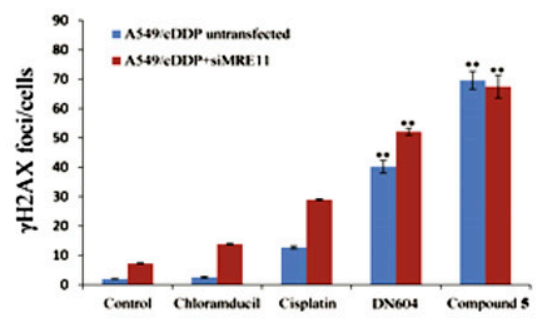

C

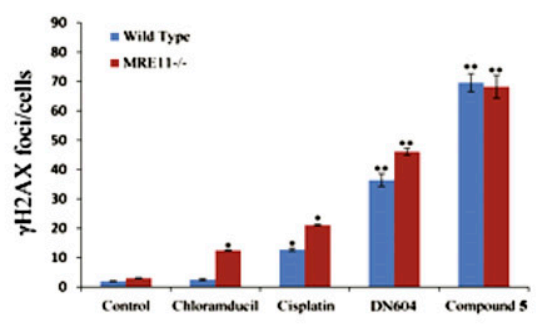

E

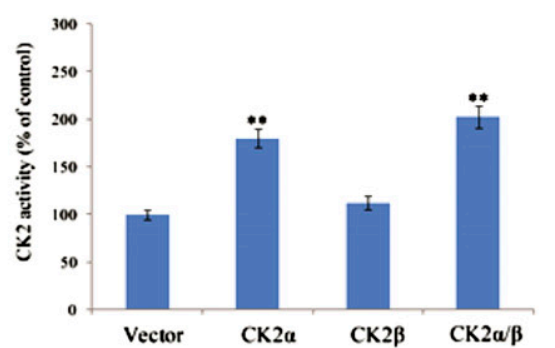

F

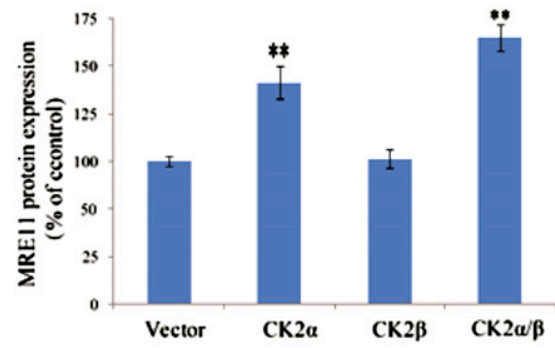

H

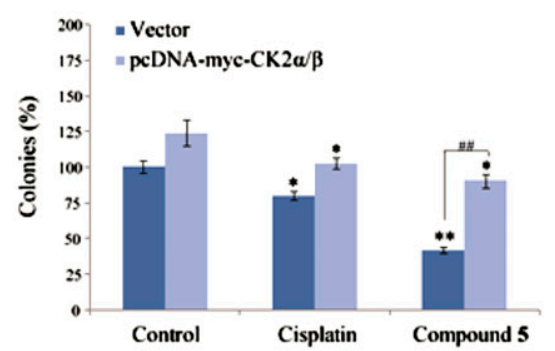

G

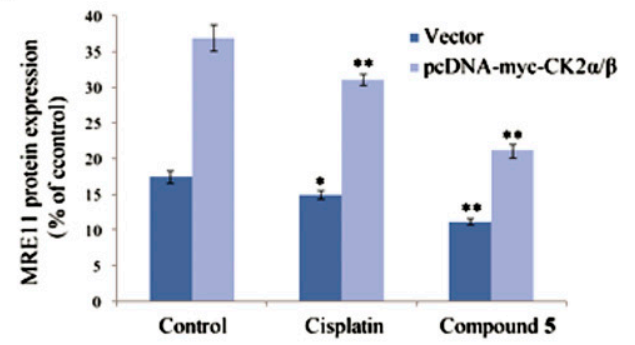

I

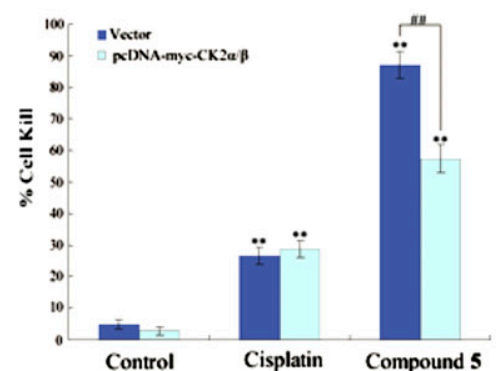

Fig. 8. Compound 5 inhibited CK2-mediated MRN complex expression. (A) Inhibition of MRE11, RAD50, and NBS1 by the measured compounds. Western blot analyses of A549/CDDP cells after treatment with chlorambucil, cisplatin, DN604, and compound $\mathbf{5}$ for 24 hours. (B) $\gamma \mathrm{H} 2 \mathrm{AX}$ foci kinetic repair after the treatment of cisplatin and compound 5. A549/CDDP cancer cells were transfected with wild-type and siMRE11 cells. Untransfected cancer cells were used as control. The $\gamma \mathrm{H} 2 \mathrm{AX}$ Foci were counted in 50-60 individual cells per time point. (C) DSB repair kinetics after the treatment of measured compounds in wild-type and MRE11 ${ }^{-/-}$ cells. Untransfected cancer cells were used as control. The $\gamma \mathrm{H} 2 \mathrm{AX}$ Foci were counted in 50-60 individual cells per time point. (D) The effect of compound 5 on CK2 activity. (E) Transient overexpression of CK2 subunits increases CK2 activity. A549/CDDP cells were transfected with empty vector, Myc-His-tagged CK2 $\alpha$, and Myc-His tagged CK2 $\beta$ or c-transfected with Myc-His-tagged CK2 $\alpha$ plus Myc-His-tagged CK2 $\beta$. (F) Overexpression of CK2 subunits increased MRE11 protein expression. A549/CDDP cells were transiently cotransfected with the CK2 subunit plasmids. (G) Overexpression of CK2 subunits increased MRE11 protein expression induced by compound 5. (H) Long-term colony formation assays of A549/CDDP cells. Cells were cotransfected with the CK2 subunit plasmids and grown in the presence of the measured compounds for 7 days. For each cell line, all dishes were fixed at the same time, stained, and analyzed. (I) Cotransfection of CK2 subunits reduced the compound 5-induced cell death. Results are representative of at least three independent experiments and shown as the mean \pm S.D. $* P<0.05 ; * * P<0.01$ compared with control group. 
A

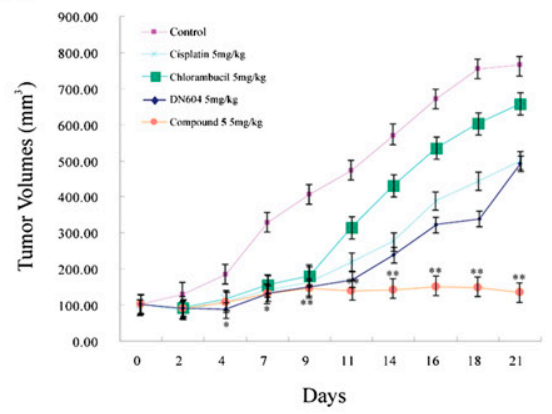

C

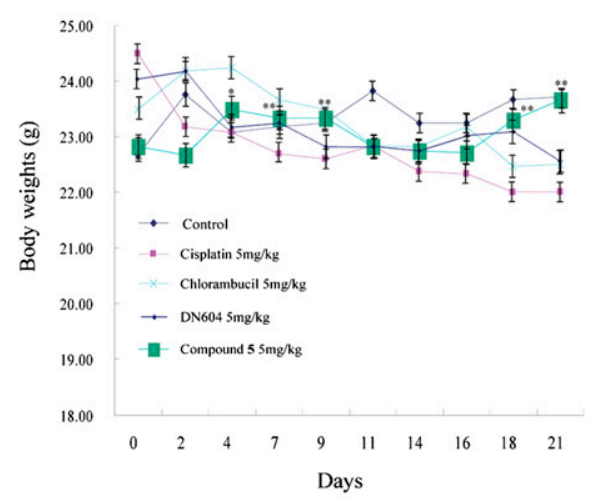

E

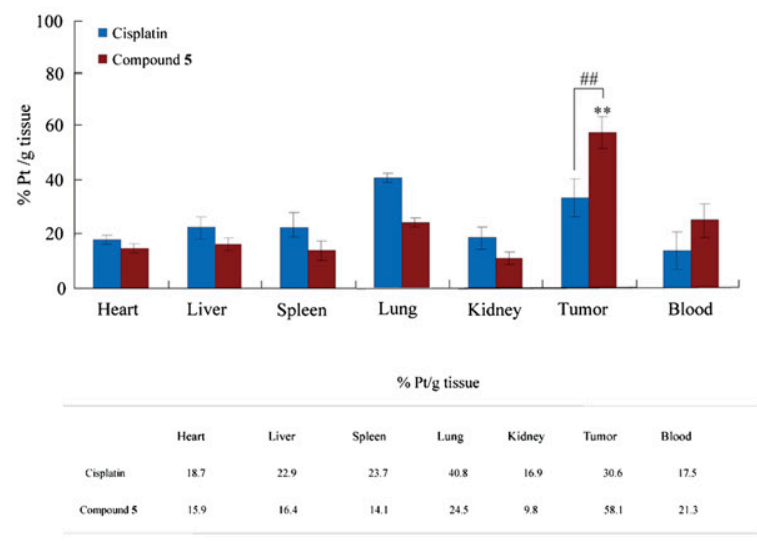

B

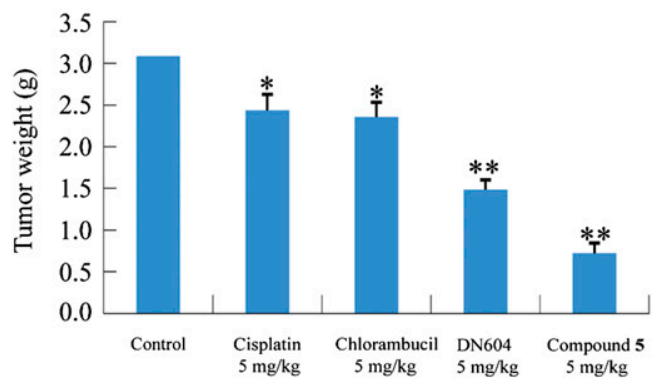

D

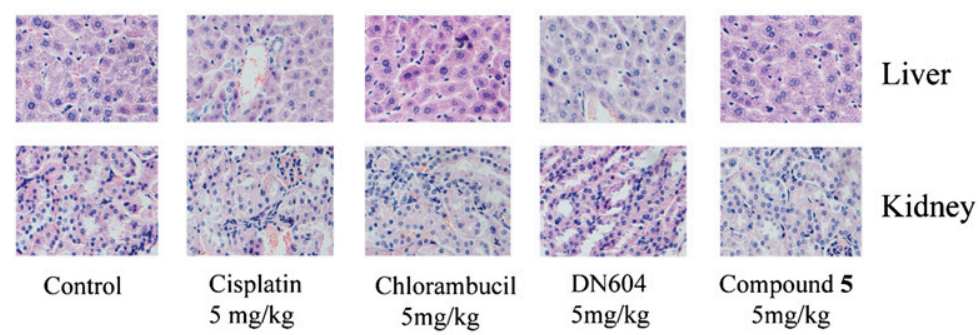

$\mathbf{F}$
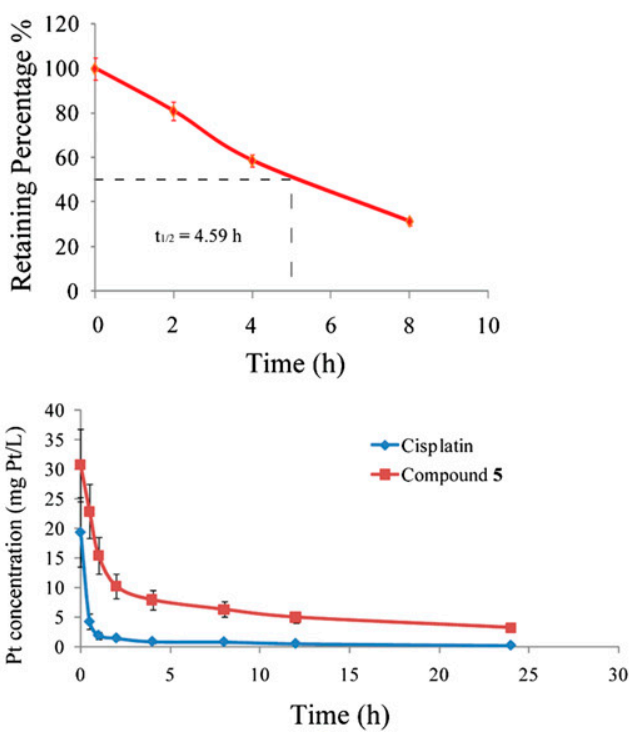

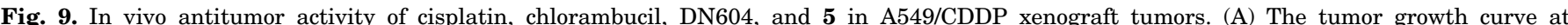

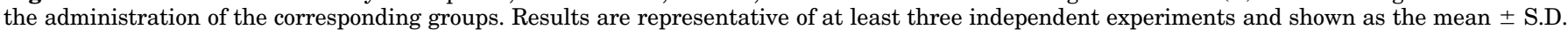

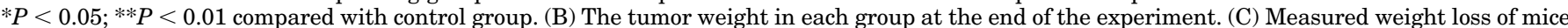

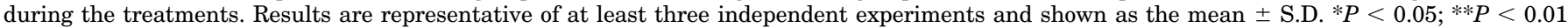

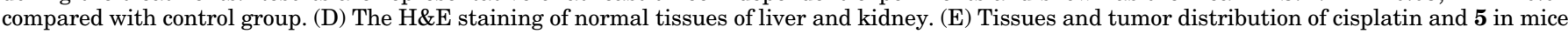

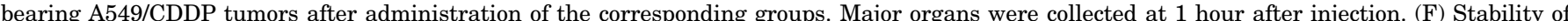

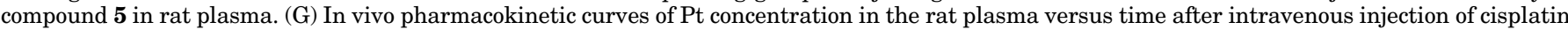

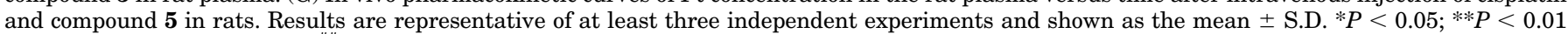
compared with control group. ${ }^{\# \#} P<0.01$ compared with cisplatin-treated group.

Compound 5 significantly exhibited the highest tumor growth inhibition among the tested samples (Fig. 9B). Because cisplatin is well known for its toxic effects on the mean bodyweights of treated animals, the body weights of mice treated with these drugs were assayed. The results in Fig. 9C illustrated that a body weight increase of the mice was observed in the compound $\mathbf{5}$ group, whereas a continuous body weight decrease of the mice was seen in the cisplatin group. The mice treated with the tested samples were selected for histologic analyses. As a result, there was no obvious 
change, pathologic injury, and inflammation infiltration in major organs of liver and kidney between control and compound 5-treated group (Fig. 9D). The H\&E staining of slices from the tissues and $\mathrm{Pt}$ uptake demonstrated that compound 5 had little toxic effect on normal tissues compared with cisplatin (Fig. 9D and E). All these data proved that compound 5 exhibits significant antitumor activity with nearly no toxic effect on treated animals in contrast to cisplatin, DN604, and chlorambucil.

Pharmacokinetics. The stability of the hybrid in blood is significantly important for its clinical application. Therefore, we investigated the stability of compound $\mathbf{5}$ in rat plasma using ICP-MS. Fresh rat plasma was added with a DMF solution of compound $5(50 \mu \mathrm{M})$. After the incubation for $0,2,4$, and 8 hours at $37^{\circ} \mathrm{C}$, the Pt content was measured by ICP-MS. The results in Fig. 9F showed that the Pt content decreased to $31.37 \%$ after an 8-hour incubation. The result reveals the halflife of compound $\mathbf{5}$ in rat plasma to be 4.59 hours, which is significantly longer than that of cisplatin ( $t_{1 / 2} \sim 30.24$ minutes). The data contributes to the promising stability of compound 5 in rat plasma. The pharmacokinetic profile of compound $\mathbf{5}$ was also performed in contrast to cisplatin. It was noticed that cisplatin and compound $\mathbf{5}$ followed a two-compartment pharmacokinetic model, which was based on the residual sum of squares and minimum Akaike's information criterion value. The results in Fig. 9G demonstrated the Pt concentration-time profiles in rat plasma, revealing the half-life of compound $\mathbf{5}$ $\left(t_{1 / 2} \sim 5.08\right.$ hours $)$ to be 2.63-fold increased compared with cisplatin ( $t_{1 / 2} 1.93$ hours). Although rapid elimination of $\mathrm{Pt}$ via blood circulation occurred in both cisplatin and compound 5treated groups, changes of these preparations were significantly different and significantly increased release time was observed in the compound 5-treated group. Notably, compound $\mathbf{5}$ had a longer blood retention compared with cisplatin, which could dramatically promote Pt accumulation in tumor tissues in the compound $\mathbf{5}$-treated group. The results could be attributed to the biodistribution of compound $\mathbf{5}$ in normal tissues as well as retention in blood circulation. Hence, compound $\mathbf{5}$ with longer circulation time could significantly improve in vivo pharmacokinetics of the corresponding $\mathrm{Pt}(\mathrm{II})$ drug and increase their bioavailability.

Upon above all the study, compound 5, possessing significant antitumor activity via reversing platinum resistance and exhibiting nearly no toxic effect, has a potential promise to be a platinum-based anticancer drug candidate.

\section{Discussion}

DNA-damaging chemotherapy is effective in the treatment of advanced cancer with a high survival benefit. However, DNA-damaging drugs as cisplatin-induced resistance remains a major obstacle to the clinical management of human solid tumor, resulting in its relapse and metastasis. As the development of platinum analogs with better therapeutic effects, carboplatin showed fewer side effects with an antitumor activity similar to that of cisplatin but shows crossresistance to cisplatin-resistant cancer cells (Sorenson and Eastman, 1988). To further overcome the acquired resistance associated with platinum-based therapies, we concomitantly developed a new Pt(II) drug, DN604, a carboplatin analog containing 3-oxocyclobutane-1,1-dicarboxylate (OCBDC) as a leaving group which has been successful in overcoming cisplatin resistance in cancer cells. Thus DN604 can be applied as one of the leading treatment options for unresponsive cisplatinbased chemotherapy in human cancer.

The lack of sensitivity to chlorambucil treatment observed in human cancer cell lines is typical. In both breast and pancreatic cancers, DSB repair mechanisms have been linked with resistance to DNA-targeted therapies (Mao et al., 2009; Li et al., 2012). Moreover, the primary mechanism of chlorambucil cytotoxicity involves the formation of N7G crosslinks (Kondo et al., 2010), inhibiting DNA synthesis and causing DSBs. Repair of persistent DNA damage induced by chlorambucil required the engagement of multiple DSB repair mechanisms that are often upregulated in chlorambucil-resistant breast and pancreatic cancer tumors. So the significant therapeutic efficacy is achieved by combining chlorambucil with agents that prevent DSB repair such as PARP inhibitors (Evers et al., 2010). In this work, we combined DN604 with a chlorambucil unit to detect its therapeutic effects on cisplatinresistant tumor both in vitro and in vivo. The hybrids were prepared by introducing the chlorambucil moiety to the axial position of the corresponding $\mathrm{Pt}(\mathrm{II})$ complexes via a linker group to deliver $\mathrm{Pt}$ and chlorambucil to tumor tissue and keep it there.

At nearly half concentrations and dosages of $\mathrm{Pt}$ and chlorambucil, compound $\mathbf{5}$ improved the ability of the drugs to kill drug-resistant A549/CDDP cells in a tumor xenograft mice model. In our study, compound 5 exhibited the dramatically high level of DNA damage that was not found in cisplatin and chlorambucil in the comet assay. The results revealed that compound $\mathbf{5}$ could increase the sensitivity of the tumor cells to cisplatin and chlorambucil and reverse drugmediated resistance by increasing their cellular uptake and suppressing MRE11-RAD50-NBS1(MRN) complex in DSB repairs. These results proved that such a conjugate between DN604 and the chlorambucil unit could not only enhance their synergistic anticancer effect but also strengthen the abilities of damaging DNA and inhibiting MRN complex-induced DSB repair.

DSBs can be recognized by the MRE11-RAD50-NBS1 (MRN) complex, which is a member of the SMC family containing ATPase domains and associates with the DNA ends of the DSBs, thus promoting the activation of ATM and the preparation of DNA for HR. In addition to stabilizing DNA ends, MRE11 has endonuclease and exonuclease activities important for the initial steps of DNA end resection that is essential for HR, as described below (Williams et al., 2007). MRE11 directly interacts with PIH1D1, which is required for the assembly of MRN complex. The MRE11-PIH1D1 interaction is dependent on casein kinase 2 (CK2) phosphorylation of two acidic sequences within the MRE11 C terminus containing serines 558/561 and 688/689. Moreover, the PIH1D1 phospho-binding domain $\mathrm{PIH}-\mathrm{N}$ is required for association with MRE11 phosphorylated by CK2. Thus depletion of CK2 resulted in MRE11 destabilization and affected DNA-damage repair processes. The results showed that the inhibition of DSB repair induced by compound $\mathbf{5}$ could be enhanced in MRE11 ${ }^{-/-}$cisplatin-resistant cancer cells (Fig. 8C), demonstrating a critical role of MRE11 in compound 5-mediated DSB repair suppression and resistance prevention, which is a novel target to augment efficacy of cancer therapies. Meanwhile, the effects of compound $\mathbf{5}$ on CK2-mediated MRE11 activity were observed in the cisplatin-resistant A549/CDDP cancer cells. 
During DSB repair, PARP1 is thought to mediate the initial accumulation of the MRN complex to DSBs in a $\gamma \mathrm{H} 2 \mathrm{AX}$ - and MDC1-independent manner (Haince et al., 2008). Moreover, PARP1 plays an initial role in the DSBs by facilitating ATM activation, while the absence of PARP1 could induce the delayed phosphorylation of ATM substrate following the treatment with DNA damaging agents. (Haince et al., 2007). The effect of compound 5 on PARP1-mediated accumulation of MRN complex in DSB repair should be determined in further studies.

Compared with known Pt(IV) complexes that could overcome cisplatin resistance as mentioned in previous reports $(\mathrm{Li}$ et al., 2015; Pichler et al., 2015; Wang et al., 2016), compound 5 exhibited lower drug resistance factor and improved in vivo safety. To sum up, introduction of chlorambucil to the Pt(IV) complexes derived from the Pt(II) complexes DN604 and DN603 has resulted in the formation of two novel Pt(IV) compounds. Among which, compound 5 presented potent cytotoxicity against two pairs of cisplatin-sensitive (SGC7901 and A549) and cisplatin-resistant (SGC-7901/CDDP and A549/CDDP) cell lines. Compound 5 was found to be highly accumulated in tumor cells for its high lipophilicity and stability as a Pt(IV) complex, and also can be readily reduced by ascorbic acid to release active drugs, DN604 and chlorambucil. Its enhanced cellular uptake of $\mathrm{Pt}$ and subsequent platinated DNA can cause extensive DSB damage, inducing cell cycle arrest and apoptosis. With the increased extent of cellular uptake after treatment of compound $\mathbf{5}$ with the cancer cells, severe DNA damage was detected as DSBs, while in contrast, most SSBs happened in cisplatin-treated cancer cells. The coordinated chlorambucil to the platinum moiety was able to significantly inhibit DSB repair with the MRE11RAD50-NBS1(MRN) complex, which related to the resistance mediated by DNA-damaging platinum-based chemotherapy drugs. The results imply that compound $\mathbf{5}$ could increase the sensitivity of the tumor cells to DN604 and reverse cisplatinmediated resistance by increasing its cellular uptake and suppressing CK2-mediated MRE11-RAD50-NBS1(MRN) complex in DSB repair. The study indicated that compound 5 possessed significant antitumor activity and had little toxicity compared with cisplatin and chlorambucil, revealing an effective strategy to promote the anticancer potency of the DNA-damaging drugs for exploring multiple targeting cancer therapies.

\section{Acknowledgments}

We are grateful to the Priority Academic Program Development of Jiangsu Higher Education Institutions for the construction of fundamental facilities. We thank the Fundamental Research Funds for the Central Universities [Project 2242016k30020] for supplying basic facilities to our key laboratory. Qin is grateful to the Innovation Program of Jiangsu Province Postgraduate Education [Project KYLX15_0128].

\section{Authorship Contributions}

Participated in research design: Gou, Chen.

Conducted experiments: Chen, Jin.

Performed data analysis: Xu, Qin.

Wrote or contributed to the writing of the manuscript: Gou, Chen.

\section{References}

Arduino DM, Esteves AR, Domingues AF, Pereira CM, Cardoso SM, and Oliveira CR (2009) ER-mediated stress induces mitochondrial-dependent caspases activation in NT2 neuron-like cells. BMB Rep 42:719-724.
Alonso-Monge R, Carvaihlo S, Nombela C, Rial E, and Pla J (2009) The Hog1 MAP kinase controls respiratory metabolism in the fungal pathogen Candidaalbicans. Microbiol 155:413-423.

Cannavo E and Cejka P (2014) Sae2 promotes dsDNA endonuclease activity within Mre11-Rad50-Xrs2 to resect DNA breaks. Nature 514:122-125.

Chabner BA, Bertino J, Cleary J, Ortiz T, Lane A, Supko JG, and Ryan D (2011) Cytotoxic agents, in Goodman and Gilman's Pharmacologic Basis of Therapeutics (Brunton LL, Chabner BA, and Knollmann BC eds), 12th ed., McGraw-Hill, NY.

Chen F, Huang X, Wu M, Gou S, and Hu W (2017) A CK2-targeted Pt(IV) prodrug to disrupt DNA damage response. Cancer Lett 385:168-178.

Chen FH, Lu N, Zhang HW, Zhao L, He LC, Sun HP, You QD, Li ZY, and Guo QL (2012) Augments tumor necrosis factor- $\alpha$-induced apoptosis via attenuating CK2dependent NF-кB pathway in HepG2 cells. Mol Pharmacol 82:958-971.

Chen FH, Zhang LB, Qiang L, Yang Z, Wu T, Zou MJ, Tao L, You QD, Li ZY, Yang Y, et al. (2010) Reactive oxygen species-mitochondria pathway involved in LYG-202-induced apoptosis in human hepatocellular carcinoma HepG(2) cells. Cancer Lett 296:96-105.

Cobo M, Isla D, Massuti B, Montes A, Sanchez JM, Provencio M, Viñolas N, Paz-Ares L, Lopez-Vivanco G, Muñoz MA, et al. (2007) Customizing cisplatin based on quantitative excision repair cross-complementing 1 mRNA expression: a phase III trial in non-small-cell lung cancer. J Clin Oncol 25:2747-2754.

Dhar S, Kolishetti N, Lippard SJ, and Farokhzad OC (2011) Targeted delivery of a cisplatin prodrug for safer and more effective prostate cancer therapy in vivo. Proc Natl Acad Sci USA 108:1850-1855.

Deng Z, Yu L, Cao W, Zheng W, and Chen T (2015) A selenium-containing ruthenium complex as a cancer radiosensitizer, rational design and the important role of ROSmediated signalling. Chem Commun (Camb) 51:2637-2640.

Déry U, Coulombe Y, Rodrigue A, Stasiak A, Richard S, and Masson JY (2008) A glycine-arginine domain in control of the human MRE11 DNA repair protein. $\mathrm{Mol}$ Cell Biol 28:3058-3069.

Evers B, Schut E, van der Burg E, Braumuller TM, Egan DA, Holstege H, Edser P, Adams DJ, Wade-Martins R, Bouwman P, et al. (2010) A high-throughput pharmaceutical screen identifies compounds with specific toxicity against BRCA2deficient tumors. Clin Cancer Res 16:99-108.

Fonseca SB, Pereira MP, Mourtada R, Gronda M, Horton KL, Hurren R, Minden MD, Schimmer AD, and Kelley SO (2011) Rerouting chlorambucil to mitochondria combats drug deactivation and resistance in cancer cells. Chem Biol 18:445-453.

Foti JJ, Devadoss B, Winkler JA, Collins JJ, and Walker GC (2012) Oxidation of the guanine nucleotide pool underlies cell death by bactericidal antibiotics. Science 336:315-319.

Fousteris MA, Koutsourea AI, Arsenou ES, Papageorgiou A, Mourelatos D, and Nikolaropoulos SS (2006) Structure-anti-leukemic activity relationship study of B- and D-ring modified and non-modified steroidal esters of chlorambucil. Anticancer Drugs 17:511-519.

Finkel T and Holbrook NJ (2000) Oxidants, oxidative stress and the biology of ageing. Nature 408:239-247.

Haince JF, McDonald D, Rodrigue A, Déry U, Masson JY, Hendzel MJ, and Poirier GG (2008) PARP1-dependent kinetics of recruitment of MRE11 and NBS1 proteins to multiple DNA damage sites. J Biol Chem 283:1197-1208.

Haince JF, Kozlov S, Dawson VL, Dawson TM, Hendzel MJ, Lavin MF, and Poirier GG (2007) Ataxia telangiectasia mutated (ATM) signaling network is modulated by a novel poly(ADP-ribose)-dependent pathway in the early response to DNAdamaging agents. $J$ Biol Chem 282:16441-16453.

Hall MD, Okabe M, Shen DW, Liang XJ, and Gottesman MM (2008) The role of cellular accumulation in determining sensitivity to platinum-based chemotherapy. Annu Rev Pharmacol Toxicol 48:495-535.

Halliwell B and Cross CE (1994) Oxygen-derived species: their relation to human disease and environmental stress. Environ Health Perspect 102 (Suppl 10):5-12.

Hansson J, Lewensohn R, Ringborg U, and Nilsson B (1987) Formation and removal of DNA cross-links induced by melphalan and nitrogen mustard in relation to druginduced cytotoxicity in human melanoma cells. Cancer Res 47:2631-2637.

Hemminki K and Ludlum DB (1984) Covalent modification of DNA by antineoplastic agents. J Natl Cancer Inst 73:1021-1028.

Huang X, Huang R, Gou S, Wang Z, Liao Z, and Wang H (2016) Combretastatin A-4 analogue: a dual-targeting and tubulin inhibitor containing antitumor Pt(IV) moiety with a unique mode of action. Bioconjug Chem 27:2132-2148.

Ishida S, Lee J, Thiele DJ, and Herskowitz I (2002) Uptake of the anticancer drug cisplatin mediated by the copper transporter Ctr1 in yeast and mammals. Proc Natl Acad Sci USA 99:14298-14302.

Klein AV and Hambley TW (2009) Platinum drug distribution in cancer cells and tumors. Chem Rev 109:4911-4920.

Kohn KW (1980) Molecular Aspects of Anti-Cancer Drug Action, pp 233-282, Macmillan, London.

Kohn KW, Hartley JA, and Mattes WB (1987) Mechanisms of DNA sequence selective alkylation of guanine-N7 positions by nitrogen mustards. Nucleic Acids Res $\mathbf{1 5}$ : 10531-10549.

Kondo N, Takahashi A, Ono K, and Ohnishi T (2010) DNA damage induced by alkylating agents and repair pathways. J Nucleic Acids 2010:543531.

Kondratskyi A, Kondratska K, Skryma R, and Prevarskaya N (2015) Ion channels in the regulation of apoptosis. Biochim Biophys Acta 1848 (10 Pt B):2532-2546.

Kuo MT, Chen HH, Song IS, Savaraj N, and Ishikawa T (2007) The roles of copper transporters in cisplatin resistance. Cancer Metastasis Rev 26:71-83.

Li Y, Deng Y, Tian X, Ke H, Guo M, Zhu A, Yang T, Guo Z, Ge Z, Yang X, et al. (2015) Multipronged design of light-triggered nanoparticles to overcome cisplatin resistance for efficient ablation of resistant tumor. ACS Nano 9:9626-9637.

Li YH, Wang X, Pan Y, Lee DH, Chowdhury D, and Kimmelman AC (2012) Inhibition of non-homologous end joining repair impairs pancreatic cancer growth and enhances radiation response. PLoS One 7:e39588.

Li ZY, Cao X, Wang X, Guo QL, and You QD (2009) Convenient synthesis of wogonin, a flavonoid natural product with extensive pharmacological activity. Org Prep Proced Int 41:327-330. 
Mao Z, Jiang Y, Liu X, Seluanov A, and Gorbunova V (2009) DNA repair by homologous recombination, but not by nonhomologous end joining, is elevated in breast cancer cells. Neoplasia 11:683-691.

von Morgen P, Burdova K, Flower TG, O'Reilly NJ, and Boulton SJ (2017) MRE11 stability is regulated by CK2-dependent interaction with R2TP complex. Oncogene 36:4943-4950

O'Grady S, Finn SP, Cuffe S, Richard DJ, O'Byrne KJ, and Barr MP (2014) The role of DNA repair pathways in cisplatin resistant lung cancer. Cancer Treat Rev 40 1161-1170.

Park MT, Kim MJ, Kang YH, Choi SY, Lee JH, Choi JA, Kang CM, Cho CK, Kang S, Bae S, et al. (2005) Phytosphingosine in combination with ionizing radiation enhances apoptotic cell death in radiation-resistant cancer cells through ROSdependent and -independent AIF release. Blood 105:1724-1733.

Pathak RK, Marrache S, Choi JH, Berding TB, and Dhar S (2014) The prodrug platin-A: simultaneous release of cisplatin and aspirin. Angew Chem Int Ed Engl 53:1963-1967.

Pichler V, Göschl S, Schreiber-Brynzak E, Jakupec MA, Galanski M, and Keppler BK (2015) Influence of reducing agents on the cytotoxic activity of platinum(IV) complexes: induction of G2/M arrest, apoptosis and oxidative stress in A2780 and cisplatin resistant A2780cis cell lines. Metallomics 7:1078-1090.

Pinton P, Giorgi C, Siviero R, Zecchini E, and Rizzuto R (2008) Calcium and apoptosis: ER-mitochondria $\mathrm{Ca}^{2+}$ transfer in the control of apoptosis. Oncogene 27: 6407-6418.

Rosenberg B, VanCamp L, Trosko JE, and Mansour VH (1969) Platinum compounds: a new class of potent antitumour agents. Nature 222:385-386.

Siddiqui-Jain A, Drygin D, Streiner N, Chua P, Pierre F, O'Brien SE, Bliesath J, Omori M, Huser N, Ho C, et al. (2010) CX-4945, an orally bioavailable selective inhibitor of protein kinase CK2, inhibits prosurvival and angiogenic signaling and exhibits antitumor efficacy. Cancer Res 70:10288-10298.

Sorenson CM and Eastman A (1988) Mechanism of cis-diamminedichloroplatinum (II)-induced cytotoxicity: role of G2 arrest and DNA double-strand breaks. Cancer Res 48:4484-4488.
Valipour M, Sefidkouhi MAG, and Eslamian S (2015) Surface irrigation simulation models: a review. Int $J$ Hydrol Science Technol 5:51-70.

Williams GJ, Lees-Miller SP, and Tainer JA (2010) Mre11-Rad50-Nbs1 conformations and the control of sensing, signaling, and effector responses at DNA doublestrand breaks. DNA Repair (Amst) 9:1299-1306.

Williams RS, Williams JS, and Tainer JA (2007) Mre11-Rad50-Nbs1 is a keystone complex connecting DNA repair machinery, double-strand break signaling, and the chromatin template. Biochem Cell Biol 85:509-520.

Wang Z, Xu Z, and Zhu G (2016) A platinum(IV) anticancer prodrug targeting nucleotide excision repair to overcome cisplatin resistance. Angew Chem Int Ed Engl 55:15564-15568.

Yannopoulos SI, Lyberatos G, Theodossiou N, Li W, Valipour M, Tamburrino A and Angelakis AN (2015) Evolution of water lifting devices (pumps) over the centuries worldwide. Water 2015:5031-5036

You QD, Li ZY, Huang CH, Yang Q, Wang XJ, Guo QL, Chen XG, He XG, Li TK, and Chern JW (2009) Discovery of a novel series of quinolone and naphthyridine derivatives as potential topoisomerase I inhibitors by scaffold modification. J Med Chem 52:5649-5661.

Yu Z, Vogel G, Coulombe Y, Dubeau D, Spehalski E, Hébert J, Ferguson DO, Masson JY, and Richard S (2012) The MRE11 GAR motif regulates DNA double-strand break processing and ATR activation. Cell Res 22:305-320.

Zhao J, Gou S, and Liu F (2014) Potent anticancer activity and possible low toxicity of platinum(II) complexes with functionalized 1,1-cyclobutanedicarboxylate as a leaving ligand. Chemistry 20:15216-15225.

Address correspondence to: Shaohua Gou, Jiangsu Province Hi-Tech Key Laboratory for Biomedical Research, Pharmaceutical Research Center and School of Chemistry and Chemical Engineering, Southeast University, Nanjing 211189, China. E-mail: sgou@seu.edu.cn 